\title{
On the Conditional Frazil Ice Instability in Seawater
}

\author{
James R. Jordan, SATOShI Kimura, PAUl R. Holland, AND AdRian JENKINS \\ British Antarctic Survey, Cambridge, United Kingdom \\ Matthew D. PiggotT \\ Department of Earth Science and Engineering, and Grantham Institute for Climate Change, Imperial \\ College London, London, United Kingdom
}

(Manuscript received 12 August 2014, in final form 21 January 2015)

\begin{abstract}
It has been suggested that the presence of frazil ice can lead to a conditional instability in seawater. Any frazil forming in the water column reduces the bulk density of a parcel of frazil-seawater mixture, causing it to rise. As a result of the pressure decrease in the freezing point, this causes more frazil to form, causing the parcel to accelerate, and so on. This study uses linear stability analysis and a nonhydrostatic ocean model to study this instability. The authors find that frazil ice growth caused by the rising of supercooled water is indeed able to generate a buoyancy-driven instability. Even in a gravitationally stable water column, the frazil ice mechanism can still generate convection. The instability does not operate in the presence of strong density stratification, high thermal driving (warm water), a small initial perturbation, high background mixing, or the prevalence of large frazil ice crystals. In an unstable water column, the instability is not necessarily expressed in frazil ice at all times; an initial frazil perturbation may melt and refreeze. Given a large enough initial perturbation, this instability can allow significant ice growth. A model shows frazil ice growth in an Ice Shelf Water plume several kilometers from an ice shelf, under similar conditions to observations of frazil ice growth under sea ice. The presence of this instability could be a factor affecting the growth of sea ice near ice shelves, with implications for Antarctic Bottom Water formation.
\end{abstract}

\section{Introduction}

Cold, dense Antarctic Bottom Water (AABW), which forms as a result of ice-ocean interaction, is one of the driving forces behind the global thermohaline circulation. A cold $\left(-1.9^{\circ} \mathrm{C}\right)$ and dense water mass known as high salinity shelf water (HSSW), generated by brine rejection from sea ice formation on the continental shelf, enters beneath cold-water glacial ice shelves such as the Filchner-Ronne and Ross (Nicholls and Østerhus 2004; Nicholls et al. 2009). The freezing temperature of seawater decreases with increasing pressure, and therefore the HSSW can melt the ice shelf at depth. The resulting meltwater cools and freshens the ambient seawater to form Ice Shelf Water (ISW), which is colder than the surface freezing

Corresponding author address: James Jordan, British Antarctic Survey, High Cross Madingley Road, Cambridge, CB3 0ET, United Kingdom.

E-mail: jamrda26@bas.ac.uk point. Density is controlled by salinity near the freezing point, and therefore the fresher ISW is lighter than the surrounding seawater. When the ISW ascends along the ice shelf, it becomes supercooled and starts to freeze because of the increase in the local freezing temperature. This ascending ISW plume is important in determining the spatial patterns of melting and freezing beneath ice shelves (Hellmer and Olbers 1989). The ascending ISW freezes both directly onto the ice shelf and through the formation of suspended frazil ice crystals. After ISW leaves the cavity, it contributes to the formation of AABW (Foldvik et al. 2004).

Frazil ice is a collection of loose, randomly oriented, disc-shaped ice crystals, formed in turbulent, supercooled water. The formation of frazil ice is a well-known phenomenon in rivers and the uppermost layers of the ocean (Martin 1981). There have also been observations at numerous Antarctic ice shelves of frazil ice up to several kilometers from the ice front, both suspended throughout the water column and present in sea ice 
cores (Dieckmann et al. 1986; Smetacek et al. 1992; Penrose et al. 1994; Leonard et al. 2006; McGuinness et al. 2009; Robinson et al. 2010). The presence of ISW during the winter at McMurdo Sound has been linked to the growth of frazil ice on the underside of sea ice (Mahoney et al. 2011), with 6-7 m observed under firstyear land-fast sea ice (Price et al. 2014).

Frazil-laden water can be considered a twocomponent mixture of ice and seawater (Jenkins and Bombosch 1995; Khazendar and Jenkins 2003; Holland and Feltham 2005). It has been suggested that the presence of frazil ice can lead to a conditional instability in seawater (Foldvik and Kvinge 1974), which proceeds as follows: Any frazil forming in the water column reduces the bulk density of a parcel of frazil-seawater mixture, causing it to rise. This rising causes the parcel to become further supercooled because of the increase in the freezing point with decreasing pressure. This causes more frazil to form, causing the parcel to accelerate, and so on. Foldvik and Kvinge (1974) analyzed this instability by considering the change in temperature of a parcel of water rising through a variety of fixed water columns, arguing that the release of cool, salty water by this convection process may reach the seabed and contribute to the formation of AABW. Although the parcel of frazil-seawater mixture is less dense than the surrounding water, this is primarily caused by the frazil ice. Once the frazil ice leaves the parcel, for example, by depositing onto the underside of sea ice, the remaining water is denser than the surrounding water because of the increased salinity from brine rejection. It is this remaining water that contributes to $\mathrm{AABW}$ formation.

For this instability to occur, there must be net ice growth as the frazil-seawater parcel rises. The frazil growth rate is determined by the thermal driving, the difference between the temperature of the seawater in the parcel and the local freezing temperature. The instability can only occur if there is a tendency for the thermal driving to decrease (become more negative) as the parcel rises. If, for example, the parcel rises into sufficiently warmer waters, the frazil could melt and the instability would then be terminated. If, on the other hand, the water column is such that a decrease in thermal driving due to the pressure release is not overcome, the instability exists. Waters that get colder towards the surface are the norm in the salt-stratified Southern Ocean.

However, this instability is not purely a function of the ambient water temperature. The rate of supercooling due to the pressure release depends upon the rate at which the parcel rises, which is determined by its buoyancy. The relative buoyancy of the parcel as it rises is determined by the density and stratification of the water column. The buoyancy is also determined by the volume of frazil in the parcel. The rate of change of buoyancy of the parcel (i.e., the tendency of perturbations to grow) is therefore determined by the frazil growth rate per unit supercooling, which is a function of the detailed geometry of the frazil ice (i.e., its surface area per unit volume). Furthermore, any tendency of the parcel to mix because of the turbulence as it rises will weaken its buoyancy and thermal contrasts and thus weaken the instability. Finally, buoyant frazil ice has a tendency to rise relative to its surrounding fluid, raising the possibility that such relative motion will negate the instability by removing the buoyancy forcing from the parcel of seawater containing the supercooling.

These considerations suggest that the frazil ice instability is far more complex than the original suggestions of Foldvik and Kvinge (1974). In particular, we expect the viability and growth rate of the instability to be governed by the rate of change of water temperature with height, the buoyancy of the perturbation, the density stratification, the details of the frazil crystal geometry, the level of turbulent mixing, and the rising of frazil relative to the surrounding seawater. The purpose of this study is to examine these effects.

We first investigate theoretically the effect of an infinitesimal perturbation on instantaneous frazil ice growth using a linear normal-mode stability analysis (section 3). This perturbation is ultimately a density perturbation but can be expressed in temperature, salinity, or frazil ice concentration. We then employ a nonhydrostatic ocean model to examine how a more realistic perturbation that is a mixture of frazil ice and freshwater evolves over time (section 4). We then use the model to investigate frazil ice growth in a scenario representing an ISW outflow from beneath an ice shelf (section 5). Finally, our conclusions are summarized (section 6).

\section{Governing equations}

We assume that the density of the fluid is represented by a two-component mixture of seawater (with a linear function of temperature $T$ and salinity $S$ ) and ice (Jenkins and Bombosch 1995). The equation of state can then be written in the form

$$
\rho=\rho_{0}(1-C)\left[1+\beta\left(S-S_{0}\right)-\alpha\left(T-T_{0}\right)\right]+\rho_{i} C,
$$

where $\rho$ is the potential density of the ice-seawater mixture; $\rho_{0}=1030 \mathrm{~kg} \mathrm{~m}^{-3}$ is the reference density of seawater; $\alpha=3.87 \times 10^{-5}{ }^{\circ} \mathrm{C}^{-1}$ is the thermal expansion coefficient; $T$ is the temperature; $T_{0}=-2^{\circ} \mathrm{C}$ is the reference temperature; $\beta=7.86 \times 10^{-4} \mathrm{psu}^{-1}$ is the 
haline contraction coefficient; $S$ is the salinity; $S_{0}=$ $34.5 \mathrm{psu}$ is the reference salinity; $\rho_{i}=920 \mathrm{~kg} \mathrm{~m}^{-3}$ is the ice density; and $C$ is the dimensionless frazil ice concentration (volume of ice per unit volume of ice-seawater mixture).

The Boussinesq Navier-Stokes equations are cast in a nonrotating Cartesian coordinate system $(x, y, z)$. The domains considered are relatively small compared to the Rossby radius of deformation, so we neglect the Coriolis effect. The resulting field equations describing the temporal evolution of the instantaneous velocity field $\mathbf{u}(x, y, z, t)=(u, v, w), T, S$, and $C$ are

$$
\begin{aligned}
\nabla \cdot \mathbf{u} & =0 \\
\frac{D \mathbf{u}}{D t} & =-\frac{1}{\rho_{m}} \nabla P-g \frac{\rho}{\rho_{m}} \hat{\mathbf{k}}+K_{v} \nabla^{2} \mathbf{u}, \\
\frac{D T}{D t} & =K_{T} \nabla^{2} T+\left(T_{c}-T-\frac{L}{c_{p}}\right) w_{c}, \\
\frac{D S}{D t} & =K_{S} \nabla^{2} S-S w_{c}, \quad \text { and } \\
\frac{D C}{D t}+w_{i} \frac{\partial C}{\partial z} & =K_{C} \nabla^{2} C-w_{c},
\end{aligned}
$$

where $D / D t=\partial / \partial t+\mathbf{u} \cdot \nabla$ is the material derivative; $g=$ $9.81 \mathrm{~m} \mathrm{~s}^{-2}$ is the acceleration due to gravity; $\rho_{m}=$ $1030 \mathrm{~kg} \mathrm{~m}^{-3}$ is the characteristic mixture density [a characteristic value of (1) following the Boussinesq approximation]; $K_{v}, K_{T}, K_{S}$, and $K_{C}$ represent the effective diffusivities of momentum, heat, salt, and frazil ice, respectively (we also define the variable $K$ to be the case when $K_{v}=K_{T}=K_{S}=K_{C}=K$ ); the variable $P$ represents the pressure; $w_{i}$ is the rising velocity of frazil ice; and $\hat{\mathbf{k}}$ is the vertical unit vector. The variable $w_{c}$ is the melt rate of frazil ice per unit volume of mixture, and it is therefore negative during ice formation (Jenkins and Bombosch 1995). While the use of $w_{c}$ to denote melt rate may be considered confusing, since frazil crystal rising velocity is denoted $w_{i}$, it has been used in previous work using the frazil ice model of Jenkins and Bombosch (1995) (Khazendar and Jenkins 2003; Holland and Feltham 2005; Jordan et al. 2014) and so has been used to maintain consistency. The second term on the right-hand sides of (4) and (5) accounts for the temperature and salinity changes in a fixed volume of the water fraction because of the frazil phase change (Holland and Feltham 2005). We note that Jordan et al. (2014) unfortunately included a sign error in their statement of (4). As we are primarily interested in the variation of freezing with depth we have omitted adiabatic heating from (4), as it has an effect an order of magnitude less than the pressure dependency of the freezing point. The freezing temperature of seawater is represented by $T_{f}$ and obeys the relation

$$
T_{f}=a S+b+c z,
$$

where $a=-0.0573^{\circ} \mathrm{Cpsu}^{-1}, b=0.0832^{\circ} \mathrm{C}$, and c $=7.61 \times$ $10^{-4 \circ} \mathrm{C} \mathrm{m}^{-1}$. The variables $L=3.35 \times 10^{5} \mathrm{~J} \mathrm{~kg}^{-1}$ and $c_{p}=$ $3974 \mathrm{~J} \mathrm{~kg}^{-1}{ }^{\circ} \mathrm{C}^{-1}$ represent the latent heat of ice fusion and specific heat capacity of seawater. It is also useful to define the thermal driving:

$$
T^{*}=T-T_{f} .
$$

When $T^{*}<0$, the water is supercooled and begins to freeze via the formation of frazil ice.

The frazil crystals are lighter than the surrounding water and therefore have an ambient rising velocity of $w_{i}$ relative to the moving fluid, approximated here by frazil's buoyant drift velocity in still water (Gosink and Osterkamp 1983):

$$
w_{i}^{2}=\frac{4 R g r a_{r}}{C_{d}},
$$

where $R=\left(\rho_{i}-\rho_{0}\right) / \rho_{0}$ is the submerged specific gravity of ice, $r$ is a characteristic radius of frazil ice discs, and $a_{r}$ is the aspect ratio of frazil ice discs. Laboratory experiments find that the distribution of frazil crystal radii takes a logarithmic form, with mean radii ranging from 0.35 to $1 \mathrm{~mm}$ (Ye et al. 2004; Clark and Doering 2006; McFarlane et al. 2014), while field observations have measured crystal radii of the order of $1 \mathrm{~cm}$ (Dieckmann et al. 1986; Robinson et al. 2010). Crystals this size would have a large rising velocity relative to the fluid they are in and are unlikely to be responsible for the instability we are investigating. As such, we have decided to focus on the smaller crystal radii and have assumed $r=$ $0.75 \mathrm{~mm}$ for our representative frazil crystal radius. Laboratory experiments also find $a_{r}=1 / 6$ (Clark and Doering 2006). The drag coefficient $C_{d}$ varies considerably with the disc Reynolds number, defined as

$$
\operatorname{Re}=\frac{w_{i} 2 r}{\nu},
$$

where $\nu=1.95 \times 10^{-6} \mathrm{~m}^{2} \mathrm{~s}^{-1}$ is the kinematic viscosity of seawater. Gosink and Osterkamp (1983) used published experimental data on the drag coefficient of discs of varying sizes to determine the following empirical relationship:

$\log _{10}\left(C_{d}\right)=1.386-0.892 \log _{10}(\mathrm{Re})+0.111\left[\log _{10}(\mathrm{Re})\right]^{2}$. 
Using an iterative method, an estimate for $w_{i}$ for a given crystal radius can be calculated from (9), (10), and (11).

We calculate $w_{c}$ by balancing heat and salt transfer through the boundary layer of each frazil crystal with the latent heat and freshwater release of melting:

$$
\begin{aligned}
& (1-C) \gamma_{T}^{c}\left(T-T_{c}\right) \frac{2 C}{r}=\frac{L}{c_{p}} w_{c}, \quad \text { and } \\
& (1-C) \gamma_{S}^{c}\left(S-S_{c}\right) \frac{2 C}{r}=w_{c} S_{c},
\end{aligned}
$$

where $\gamma_{T}^{c}$ and $\gamma_{S}^{c}$ are the ocean heat and salt transfer coefficients at the edge of frazil ice crystals. For transfer at the disc edges, the appropriate length scale is the halfthickness of the disc (Daly 1994), so we calculate the transfer coefficients as follows:

$$
\gamma_{T}^{c}=\frac{\mathrm{Nu} \kappa_{T}}{a_{r} r}, \quad \gamma_{S}^{c}=\frac{\mathrm{Nu} \kappa_{S}}{a_{r} r},
$$

where $\kappa_{T}=1.4 \times 10^{-7} \mathrm{~m}^{2} \mathrm{~s}^{-1}$ is the molecular thermal diffusivity of seawater, $\kappa_{S}=8 \times 10^{-10} \mathrm{~m}^{2} \mathrm{~s}^{-1}$ is the molecular haline diffusivity of seawater, $\mathrm{Nu}$ is the dimensionless Nusselt number, and we assume $\mathrm{Nu}=1$. The temperature $T_{c}$ and salinity $S_{c}$ at the ice-ocean interface at the edge of a frazil crystal is assumed to be at the freezing temperature:

$$
T_{c}=a S_{c}+b+c z_{c} .
$$

\section{Linear normal-mode stability analysis}

\section{a. Introduction}

We first consider a linear stability analysis, which applies an infinitesimally small perturbation to the system (2)-(6). The object of this exercise is to understand under what conditions the perturbation will grow and the frazil-led seawater instability exist. The advantage of this approach is that it allows a clear account of the initiation of the instability and a concrete determination of the conditions under which the system is unstable. A disadvantage is that the approach only elucidates the initial behavior of the perturbation where a linear assumption is valid. In later sections, we use a numerical solution of the nonlinear equations to investigate the full evolution.

Below, we formulate an eigenvalue problem to determine the growth rate of perturbations within the system. We then examine the system stability by considering perturbation growth or decay for a range of values for the background stratification $d \bar{\rho} / d z$ and the

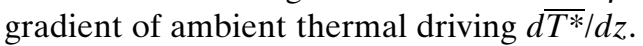

\section{b. Perturbation}

We hypothesize that variability caused by the vertical distribution of density and thermal driving drive the instability. We therefore define a stagnant background state in which $T, S, C$, and $P$ vary in $z$. The instantaneous temperature, salinity, frazil concentration, and pressure terms are separated into two parts, a background profile and a perturbation, while the background flow is assumed to be zero:

$$
\begin{aligned}
\mathbf{u} & =(u, v, w), \\
\mathbf{u} & =\epsilon \mathbf{u}^{\prime}(x, y, z, t), \\
T & =\bar{T}(z)+\epsilon T^{\prime}(x, y, z, t), \\
S & =\bar{S}(z)+\epsilon S^{\prime}(x, y, z, t), \\
C & =\bar{C}(z)+\epsilon C^{\prime}(x, y, z, t), \quad \text { and } \\
P & =\bar{P}(z)+\epsilon P^{\prime}(x, y, z, t) .
\end{aligned}
$$

We substitute (16)-(21) into (1)-(6) and then collect the $O(\epsilon)$ terms to yield equations governing the evolution of the perturbation:

$$
\begin{aligned}
\frac{\partial u^{\prime}}{\partial t}= & -\frac{1}{\rho_{m}} \frac{\partial P^{\prime}}{\partial x}+K_{v} \nabla^{2} u^{\prime} \\
\frac{\partial v^{\prime}}{\partial t}= & -\frac{1}{\rho_{m}} \frac{\partial P^{\prime}}{\partial y}+K_{v} \nabla^{2} v^{\prime} \\
\frac{\partial w^{\prime}}{\partial t}= & -\frac{1}{\rho_{m}} \frac{\partial P^{\prime}}{\partial z}-g(1-\bar{C}) \frac{\rho_{0}}{\rho_{m}}\left[\beta S^{\prime}-\alpha T^{\prime}\right] \\
& +g \frac{\rho_{0}}{\rho_{m}} C^{\prime}\left[1+\beta\left(\bar{S}-S_{0}\right)-\alpha\left(\bar{T}-T_{0}\right)\right] \\
& -g \frac{\rho_{i}}{\rho_{m}} C^{\prime}+K_{v} \nabla^{2} w^{\prime},
\end{aligned}
$$

$$
\begin{aligned}
\frac{\partial T^{\prime}}{\partial t}+w^{\prime} \frac{\partial \bar{T}}{\partial z}= & K_{T} \nabla^{2} T^{\prime}+\bar{w}_{c}\left(a S^{\prime}-T^{\prime}\right) \\
& +w_{c}^{\prime}\left(a \bar{S}+b+c z-\bar{T}-\frac{L}{c_{p}}\right), \text { and }
\end{aligned}
$$

$$
\frac{\partial S^{\prime}}{\partial t}+w^{\prime} \frac{\partial \bar{S}}{\partial z}=K_{S} \nabla^{2} S^{\prime}-\overline{w_{c}} S^{\prime}-\bar{S} w_{c}^{\prime},
$$

where $w_{c}=\bar{w}_{c}+w_{c}^{\prime}$, with $w_{c}^{\prime}$ as the perturbation frazil growth calculated from substituting (18)-(20) into (12)(15). We note that the ratio $\rho_{0} / \rho_{m}$ is only included for clarity in (24), as $\rho_{0}=\rho_{m}$. All the perturbations are assumed to take the normal-mode form: 


$$
\left[\begin{array}{c}
u^{\prime} \\
v^{\prime} \\
w^{\prime} \\
T^{\prime} \\
S^{\prime} \\
C^{\prime}
\end{array}\right]=\left[\begin{array}{c}
\hat{u}(z) \\
\hat{v}(z) \\
\hat{w}(z) \\
\hat{T}(z) \\
\hat{S}(z) \\
\hat{C}(z)
\end{array}\right] e^{\sigma t+i(k x+l y)},
$$

where $k$ and $l$ are wavenumbers in the streamwise and spanwise directions, respectively, and $\sigma$ is the growth rate of the perturbation. Substituting these perturbations into the $O(\epsilon)$ equations and eliminating $P^{\prime}$ terms by taking the Laplacian of the vertical momentum equation gives

$$
\begin{aligned}
\sigma \bar{\nabla}^{2} \hat{w}= & g(1-\bar{C}) \frac{\rho_{0}}{\rho_{m}} \tilde{k}^{2}(\beta \hat{S}-\alpha \hat{T})-g \frac{\rho_{0}}{\rho_{m}}\left[1+\beta\left(\bar{S}-S_{0}\right)\right. \\
& \left.-\alpha\left(\bar{T}-T_{0}\right)\right] \tilde{k}^{2} \hat{C}+g \frac{\rho_{i}}{\rho_{m}} \tilde{k}^{2} \hat{C}+K_{v} \bar{\nabla}^{4} \hat{w}
\end{aligned}
$$

$$
\begin{aligned}
\sigma \hat{T}= & -\frac{d \bar{T}}{d z} \hat{w}+K_{T} \bar{\nabla}^{2} \hat{T}+\bar{w}_{c} a \hat{S}-\bar{w}_{c} \hat{T} \\
& +\left(a \bar{S}+b+c z-\bar{T}-\frac{L}{c_{p}}\right) \hat{w}_{c}, \\
\sigma \hat{S}=- & -\frac{d \bar{S}}{d z} \hat{w}+K_{S} \bar{\nabla}^{2} \hat{S}-\bar{w}_{c} \hat{S}-\bar{S}_{\hat{w}_{c}}, \quad \text { and } \\
\sigma \hat{C}=- & \frac{d \bar{C}}{d z} \hat{w}-w_{i} \frac{d \hat{C}}{d z}+K_{C} \bar{\nabla}^{2} \hat{C}-\hat{w}_{c},
\end{aligned}
$$

where $\bar{\nabla}^{2}=\left(d^{2} / d z^{2}\right)-\tilde{k}^{2}$ and $\tilde{k}^{2}=k^{2}+l^{2}$. The variable $\hat{w}_{c}$ represents the perturbation of the frazil growth rate, which is a function of $\hat{T}, \hat{S}$, and $\hat{C}$ :

$$
\begin{aligned}
\widehat{w_{c}}= & \frac{2 \gamma_{T} c_{p}}{L r} \bar{C}(1-\bar{C}) \hat{T}-a \overline{S_{c}} \frac{4 \gamma_{T}^{2} c_{p}^{2}}{A r^{2} L^{2}} \bar{C}^{2}(1-\bar{C})^{2} \hat{T}+\frac{4 a \gamma_{T} \gamma_{S} c_{p}}{A L r^{2}} \bar{C}^{2}(1-\bar{C})^{2} \hat{S}+\frac{2 \gamma_{T} c_{p}}{L r}(1-2 \bar{C})\left(\bar{T}-\overline{T_{c}}\right) \hat{C} \\
& -\frac{4 a \gamma_{T} c_{p}}{A L r^{2}}(1-2 \bar{C}) \bar{C}(1-\bar{C})\left[\frac{\overline{S_{c}} \gamma_{T} c_{p}}{L}\left(\bar{T}-\overline{T_{c}}\right)-\gamma_{S}\left(\bar{S}-\overline{S_{c}}\right)\right] \hat{C}
\end{aligned}
$$

where

$A=\frac{2 \overline{S_{c}} \gamma_{T} c_{p}}{r L} a \bar{C}(1-\bar{C})-\frac{2 \gamma_{S}}{r} \bar{C}(1-\bar{C})-\overline{w_{c}}$.

Equations (28)-(33) form a closed, generalized, differential eigenvalue problem whose eigenvalue is $\sigma$ and whose eigenvector is the concatenation of $\{\hat{w}(z), \hat{T}(z)$, $\hat{S}(z), \hat{C}(z)\}$. We solve this eigenvalue problem numerically to determine the growth or decay of perturbations under a variety of conditions.

\section{c. Background profile}

The background gradient of thermal driving $d \overline{T^{*}} / d z$ regulates the rate at which a rising parcel is able to produce frazil ice. In the case of high $d \overline{T^{*}} / d z$, the rising may not produce enough supercooling to sustain the growth of frazil. Also, in the presence of sufficiently negative background stratification $d \bar{\rho} / d z$, frazil production may not be able to overcome the stratification and maintain a positive buoyancy anomaly in the parcel relative to its surroundings. We test these ideas in a highly idealized configuration loosely representing an ISW outflow of supercooled water from the deepest part of an ice shelf cavity. We wish to prescribe $d \bar{\rho} / d z$ and $d \overline{T^{*}} / d z$, so we assume $\bar{C}$ is uniform in space and construct linear profiles of $\bar{T}$ and $\bar{S}$ from the following relations:

$$
\begin{aligned}
\frac{d \bar{\rho}}{d z} & =\rho_{0}(1-\bar{C})\left(\beta \frac{d \bar{S}}{d z}-\alpha \frac{d \bar{T}}{d z}\right), \quad \text { and } \\
\frac{d \overline{T^{*}}}{d z} & =\frac{d \bar{T}}{d z}-a \frac{d \bar{S}}{d z}+c .
\end{aligned}
$$

Solving the two equations above, we obtain $d \bar{T} / d z$ and $d \bar{S} / d z$ for given $d \bar{\rho} / d z, d \overline{T^{*}} / d z$, and $\bar{C}$. These $d \bar{T} / d z$ and $d \bar{S} / d z$ are integrated with respect to $z$ from the middepth where we specify thermal driving $\overline{T^{*}}(z=0)$ and density $\rho_{m}$ to obtain linear profiles of $\bar{T}$ and $\bar{S}$.

Cool, fresh water is formed beneath ice shelves because of the melting of ice and exits the cavity at depth at the ice front (Jacobs et al. 1979). We consider the presence of freezing temperature water at $z=0$ in an idealized domain between $z=-200 \mathrm{~m}$ and $z=200 \mathrm{~m}$. Thermal driving increases toward the top and bottom, that is, $\left(d \overline{T^{*}} / d z\right)>0$ for $z>0$ and $\left(d \overline{T^{*}} / d z\right)>0$ for $z<0$ (Fig. 1a). The salinity gradient changes at $z=0$ (Fig. 1b) to maintain a uniform density gradient (Fig. 1c). This somewhat artificial setup is chosen so that the background profile of the system depends upon single values for $d \overline{T^{*}} / d z, d \bar{\rho} / d z, \overline{T^{*}}(z=0)$, and $\bar{C}$. The stability of the 
(a)

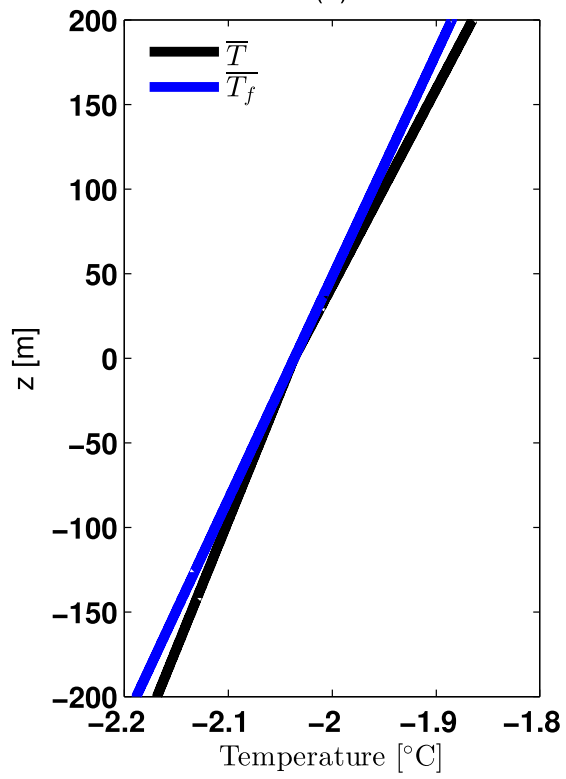

(b)

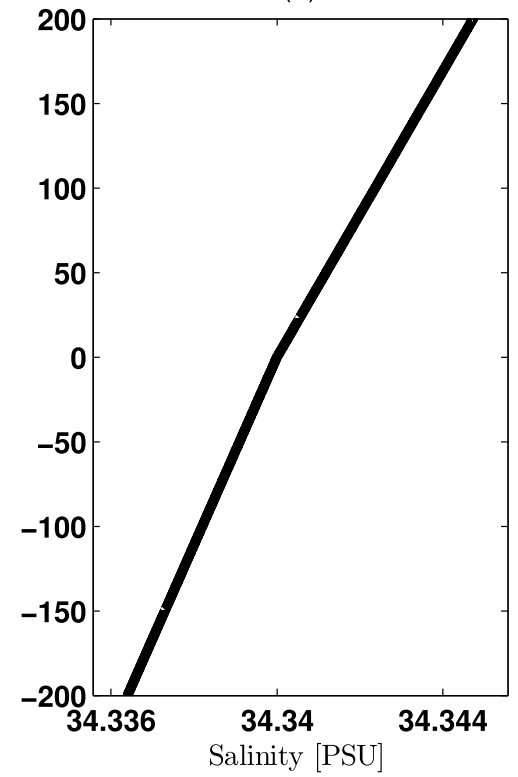

(c)

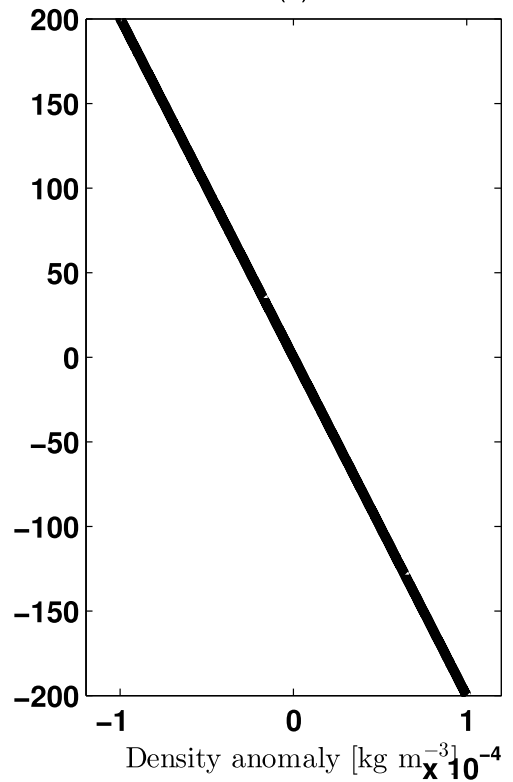

FIG. 1. Setup of the linear stability analysis. Background profiles of (a) $\bar{T}$ and $\overline{T_{f}}$, (b) $\bar{S}$, and (c) $\bar{\rho}-\rho_{m}$ with $\left|d \overline{T^{*}} / d z\right|=10^{-4{ }^{\circ}} \mathrm{Cm}{ }^{-1}$, $d \bar{\rho} / d z=-0.5 \times 10^{-6} \mathrm{~kg} \mathrm{~m}^{-4},\left.\overline{T^{*}}\right|_{z=0}=0$, and $\bar{C}=10^{-8}$.

system with respect to $d \overline{T^{*}} / d z$ and $d \bar{\rho} / d z$ is described below.

\section{d. Overview of instabilities}

Equations (28)-(33) depend on $\tilde{k}^{2}$ rather than the individual $k$ and $l$, so any combination of horizontal wavenumbers $(k, l)$ with the same $\tilde{k}$ gives the same growth rate; the growth rate depends on the magnitude of the wave vector but not on its direction. This feature is also present in the stability problems of the doublediffusive (Schmitt 1994) and ordinary convection (Linden 2000) systems. The horizontal shape of the convection cells is not determined by the linear normalmode stability analysis, so we consider the stability properties for $k=0$.

Background shear is absent, so our system is subjected only to a buoyancy-driven instability. The buoyancy is controlled by temperature, salinity, and frazil concentration, and we assume that diffusivities of heat and salt are the same $\left(K_{T}=K_{S}\right)$, which eliminates any possibility of doublediffusive instability. When the stratification is unstable $(d \bar{\rho} / d z)>0$, Rayleigh-Benard convection occurs, and so the system is unstable, that is, the real part of the growth rate is positive, $\sigma_{r}>0$ (Fig. 2).

Rayleigh-Benard convection cannot drive instability in the presence of stable stratification $(d \bar{\rho} / d z)<0$; however, our system features a frazil-driven instability

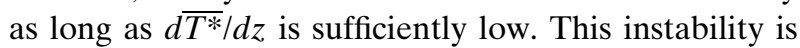
governed by a competition between $d \bar{\rho} / d z$ and $d \overline{T^{*}} / d z$.
As $d \overline{T^{*}} / d z$ increases, a rising parcel of fluid will experience a progressively greater warming (relative to the freezing temperature) and the production of frazil ice is progressively suppressed.

In the absence of frazil ice, the stability problem reduces to (28)-(33) with $\overline{w_{c}}=\bar{C}=\hat{w}_{c}=\hat{C}=0$. For the linear background stratification used here, the eigenvalue problem becomes a quadratic equation for $\sigma$; the classic Rayleigh-Benard convection problem (e.g., Linden 2000). The influence of frazil ice on the stability of the system decreases with increasing $d \overline{T^{*}} / d z$, because of the inability of frazil to grow, so the $\sigma_{r}$ of the fastest growing mode converges with the case of pure convection (Fig. 2b).

In an attempt to quantify the relative importance of frazil production to the instability, we analyze the sources of perturbation kinetic energy, defined as

$$
K_{p}=\frac{1}{2}\left\langle\mathbf{u}^{\prime} \cdot \mathbf{u}^{\prime}\right\rangle_{x y},
$$

where the angle bracket and subscript denote a horizontal average. The time rate of change in perturbation kinetic energy is obtained by taking the scalar product of $\mathbf{u}^{\prime}$ with the (perturbation) momentum equations (22)(24). The resulting equation is

$$
\frac{\partial K_{p}}{\partial t}+\nabla \cdot F=B_{C}+B_{T S}+\epsilon_{d}
$$

where the second term on the left-hand side is the divergence of a sum of advective, pressure-driven, and 

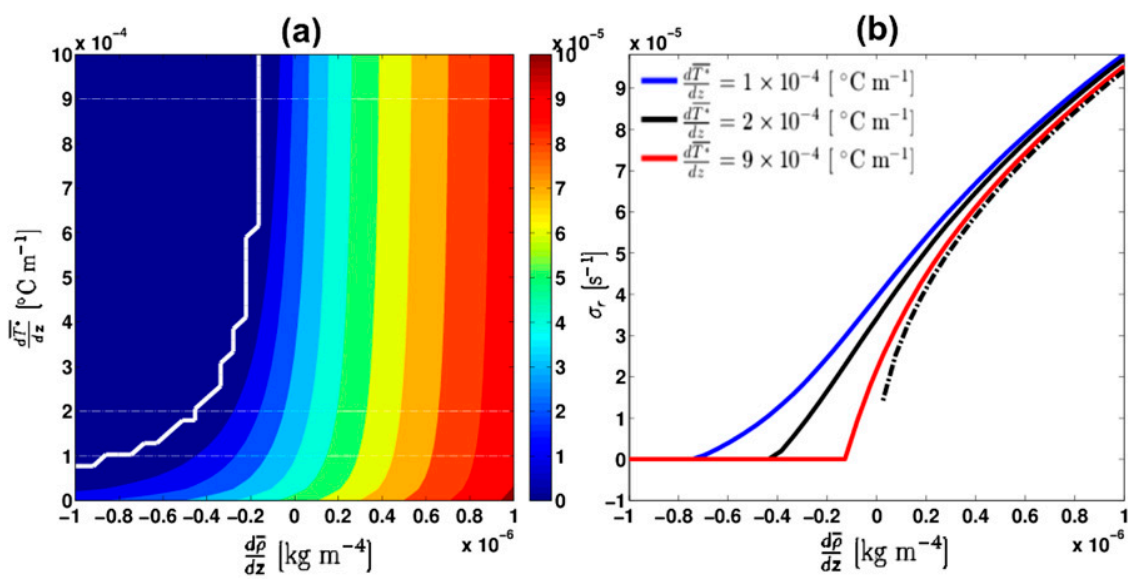

FIG. 2. Growth of perturbation in the linear stability analysis. (a) The real part of $\sigma\left(\mathrm{s}^{-1}\right), \sigma_{r}$ with respect to $d \bar{T}^{*} / d z, d \bar{\rho} / d z$, and all other parameters held constant; (b) $\sigma_{r}$ with respect to $d \bar{\rho} / d z$ for different $d / d z\left(\bar{T}-\overline{T_{f}}\right)$. The white curve in (a) is the stability boundary, where $\sigma_{r}=0$. The white horizontal lines in (a) indicate $d \bar{T}^{*} / d z$ used in (b). The dark dashed curve in (b) is the fastest growing mode of Rayleigh-Benard convection.

viscous fluxes. These terms vanish when the spatial average is taken, and we will not consider them further. The terms $B_{C}$ and $B_{T S}$ are the buoyancy production terms by frazil ice and temperature and salinity, respectively, defined as

$$
\begin{aligned}
B_{C}= & g\left(\frac{\rho_{i}+\rho_{0}}{\rho_{m}}\right)\left\langle w^{\prime} C^{\prime}\right\rangle_{x y}+g \frac{\rho_{0}}{\rho_{m}}\left\langle\left[\beta\left(\bar{S}-S_{0}\right)\right.\right. \\
& \left.\left.-\alpha\left(\bar{T}-T_{0}\right)\right] w^{\prime} C^{\prime}\right\rangle_{x y}, \quad \text { and } \\
B_{T S}= & -g(1-\bar{C}) \frac{\rho_{0}}{\rho_{m}}\left[\beta\left\langle w^{\prime} S^{\prime}\right\rangle_{x y}-\alpha\left\langle w^{\prime} T^{\prime}\right\rangle_{x y}\right] .
\end{aligned}
$$

The variable $\epsilon_{d}$ is the perturbation kinetic energy dissipation rate, defined as

$$
\epsilon_{d}=-2 K_{v}\left\langle e_{i, j} e_{i, j}\right\rangle_{x y}, \quad e_{i, j}=\frac{1}{2}\left(\frac{\partial u_{i}^{\prime}}{\partial x_{j}}+\frac{\partial u_{j}^{\prime}}{\partial x_{i}}\right) .
$$

The amplitudes of the fluxes are arbitrary in the linear regime, but their ratio is not. We consider the evolution of the total perturbation kinetic energy budget over time using an instantaneous vertically averaged exponential growth rate:

$$
\sigma=\frac{1}{2\left\langle K_{p}\right\rangle_{z}} \frac{d\left\langle K_{p}\right\rangle_{z}}{d t}
$$

The relative importance of the perturbation kinetic energy sources on the right-hand side of (37) is quantified by partial growth rates of the form

$$
\sigma_{C}=\frac{\left\langle B_{C}\right\rangle_{z}}{2\left\langle K_{p}\right\rangle_{z}}
$$

and similarly for the buoyancy production by temperature and salinity $\sigma_{T S}$ and associated with dissipation $\sigma_{d}$. The $K_{p}$ budget can then be written as

$$
\sigma=\sigma_{T S}+\sigma_{C}+\sigma_{d} .
$$

Because $\sigma_{d}$ is negative, $K_{p}$ grows because of the buoyancy production terms $\sigma_{T S}$ and $\sigma_{C}$. In the absence of frazil ice, the work is done by the fluctuations of temperature and salinity on the fluid, so $\sigma_{T S}$ is the only source of buoyancy production. The variable $\sigma_{C}$ represents the work done by fluctuations of frazil concentration.

\section{1) WHAT IS THE INSTABILITY REGIME FOR $(d \bar{\rho} / d z)>0$ ?}

When $(d \bar{\rho} / d z)>0$, the water column is unstable and convection occurs. The fastest growing mode of convection with a linear background profile of density is a classic Rayleigh-Benard problem, and the growth rate of this problem has an analytical solution (e.g., Linden 2000). The influence of the convection is evident in the budget of partial growth rates. The potential energy stored in an unstable stratification is released via $\sigma_{T S}$, while the contribution to $\sigma$ from $\sigma_{C}$ decreases with increasing $d \bar{\rho} / d z$ (Fig. 3a). When the water column is sufficiently unstable $B_{T S}$ generates more turbulent kinetic energy than $B_{C}$ (Fig. 3c). The density gradient is uniform in space (Fig. 1c), whereas the supercooled water is concentrated at the center and the thermal driving increases away from the center (Fig. 1a). Thus, the disturbance from $B_{T S}$ can grow over a wider area than that of $B_{C}$ in unstable conditions (Fig. 3c). 


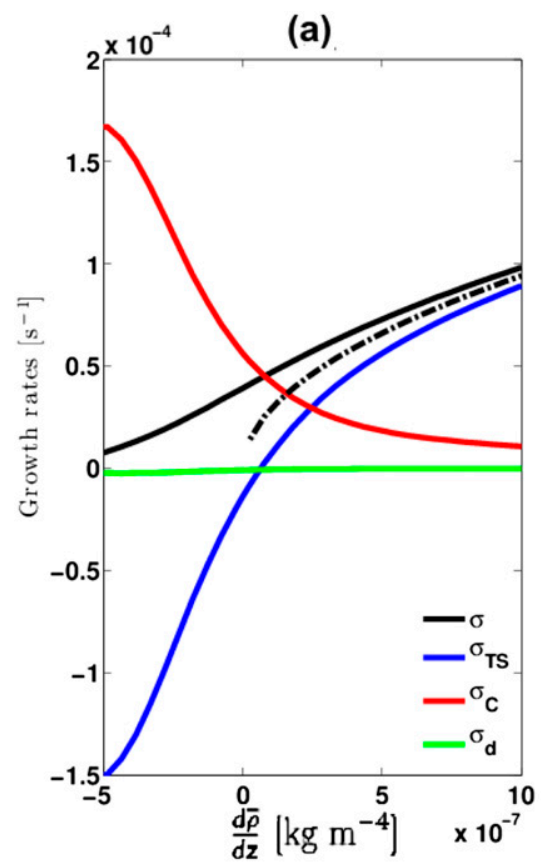

(b)

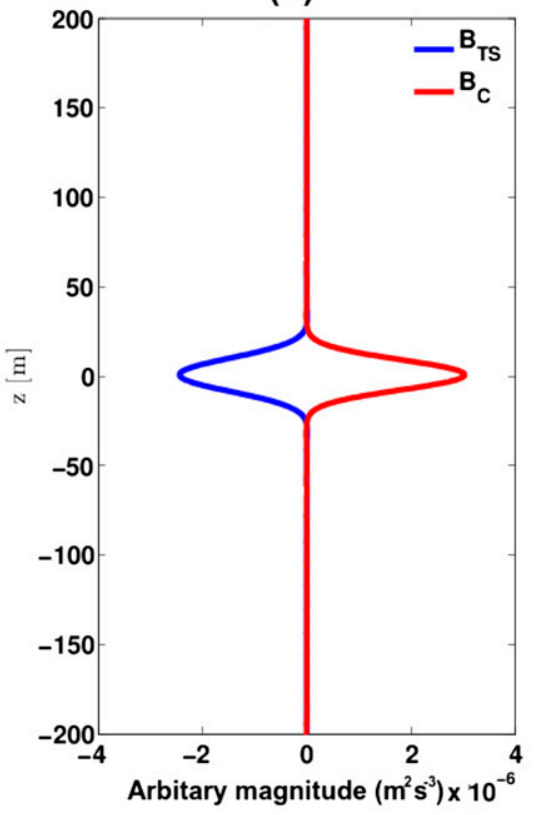

(c)

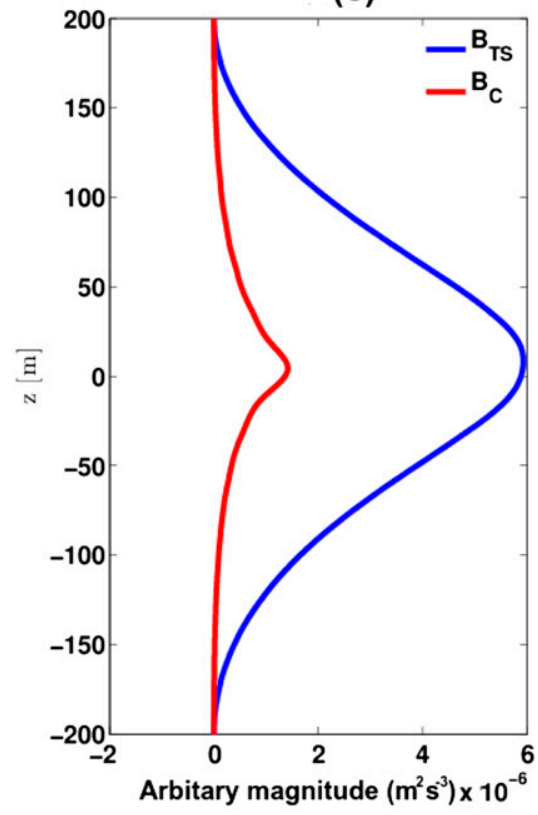

FIG. 3. Growth of perturbation in the linear stability analysis. (a) Partial growth rates with respect to $d \overline{\rho_{z}} / d z$ at $d \overline{T^{*}} / d z=1 \times 10^{-4{ }^{\circ}} \mathrm{C} \mathrm{m}^{-1}$. The dashed line indicates the growth rate for the Rayleigh-Benard convection. Profiles of $B_{T S}$ and $B_{C}$ at (b) $d \overline{\rho_{z}} / d z=-0.5 \times 10^{-6} \mathrm{~kg} \mathrm{~m}^{-4}$ and (c) $d \overline{\rho_{z}} / d z=1 \times 10^{-6} \mathrm{~kg} \mathrm{~m}^{-4}$. The terms $B_{T S}$ and $B_{C}$ are derived from the perturbations and are $O\left(\epsilon^{2}\right)$ terms. The linear stability analysis does not specify the magnitude of $\epsilon$. The exact magnitude of $B_{T S}$ and $B_{C}$ are dictated by the value of $\epsilon$ and are unknown, so we do not specify the physical units in (b) and (c). Because $\epsilon$ is spatially uniform, the profiles represent the vertical distribution of $B_{T S}$ and $B_{C}$.

It is interesting to note that the convection does not start to dominate the instability regime at $(d \bar{\rho} / d z)=0$. For $d \overline{T^{*}} / d z=10^{-4 \circ} \mathrm{Cm}^{-1}$, the contribution to $\sigma$ from $\sigma_{T S}$ only exceeds $\sigma_{C}$ for $\left(d \overline{\rho_{z}} / d z\right)>0.2 \times 10^{-6} \mathrm{~kg} \mathrm{~m}^{-4}$ (Fig. 3a), and $\sigma$ subsequently converges rapidly to the growth rate of the Rayleigh-Benard convection. The frazil ice-driven instability and the convection coexist when $d \overline{\rho_{z}} / d z$ is between 0 and $0.2 \times 10^{-6} \mathrm{~kg} \mathrm{~m}^{-4}$, and the fastest growing mode has a growth rate that is higher than that of pure convection (Fig. 3a).

\section{2) WHAT IS THE INSTABILITY REGIME FOR $(d \bar{\rho} / d z)<0$ ?}

When $(d \bar{\rho} / d z)<0$, the water column is stably stratified, so the background convection cannot play a role in the instability and $\sigma_{T S}<0$ (Fig. 3a). In this case, the change in buoyancy because of frazil growth $\sigma_{C}$ acts as a reservoir of turbulent kinetic energy, driving the instability. As $(d \bar{\rho} / d z)<0$ becomes more negative (stable), the total instability growth rate becomes smaller (Figs. 2, $3 a)$. Frazil growth drives a progressively larger fraction of the instability because the background stratification suppresses the growth rate to a progressively larger degree. Eventually the instability is suppressed altogether and the growth rate becomes zero.
In the presence of stable background stratification, $B_{T S}$ is negative and supercooling generates the turbulent kinetic energy through $B_{C}$ (Fig. 3a). The instabilities grow from the center of the domain, where the perturbation of the water column generates supercooled water (Fig. 3b).

\section{Numerical modelling of an idealized instability}

\section{a. Model setup}

Having investigated the linear stability of an instantaneous infinitesimal perturbation, we now consider the full evolution of the system response to a finite density perturbation. Section 3 considered a frazil ice instability that ranged from "pure," in which the background stratification was stable and the instability was purely frazil led, to "mixed," in which the background stratification was unstable and the frazil enhanced the underlying gravitational instability. In reality ISW plumes are a mixture of frazil ice and water that is relatively fresher than its surroundings, leading to a density perturbation composed of both frazil ice and a "fresh anomaly." This results in a mixed type instability, and it is this more realistic combination of a frazil and fresh 

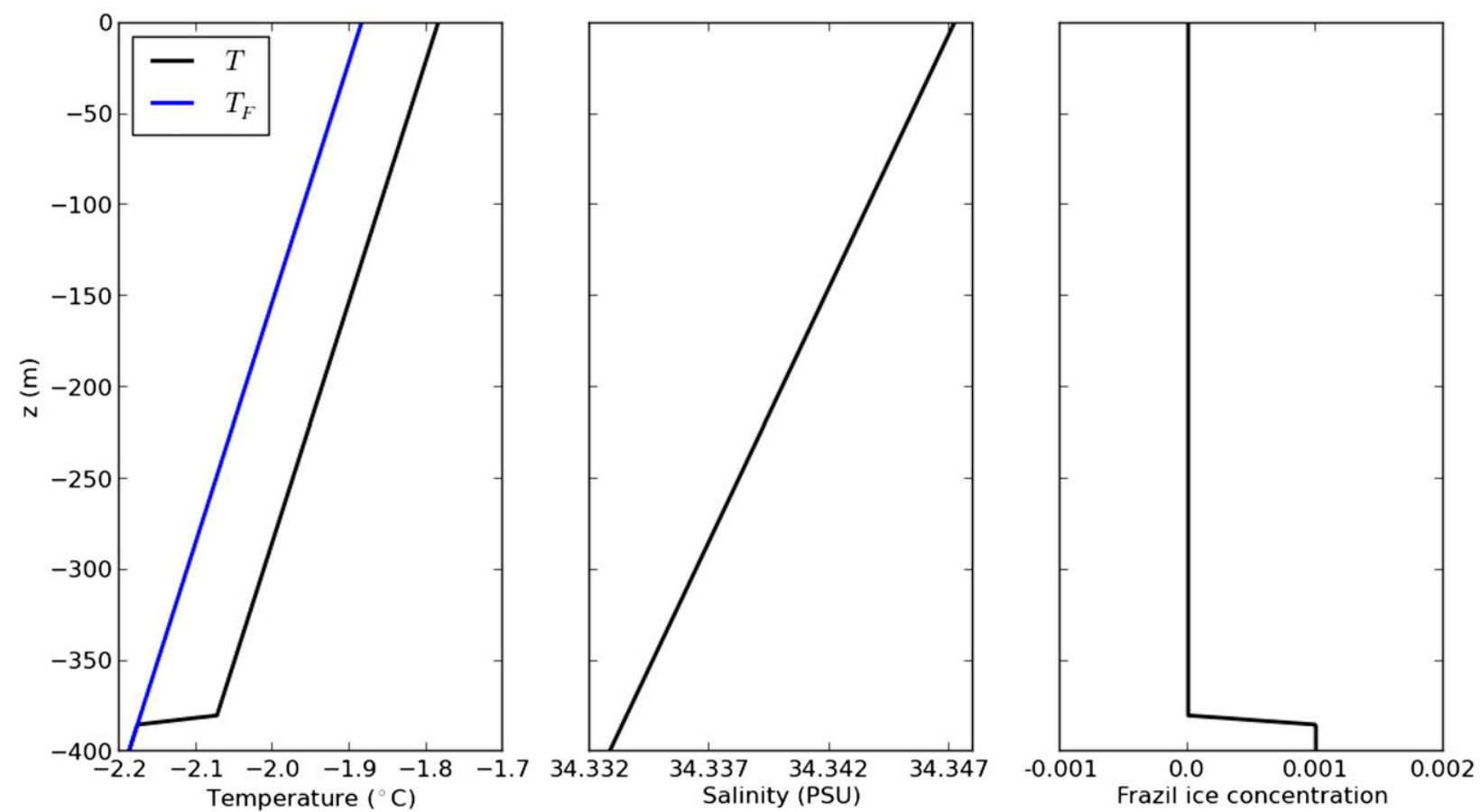

FIG. 4. Idealized, nonhydrostatic ocean model setup. Initial profiles for the baseline case $\left(T_{\text {in }}^{*}=10^{-1 \circ} \mathrm{C}, \partial \rho / \partial z_{\text {in }}=-10^{-5} \mathrm{~kg} \mathrm{~m}^{-4}, C_{\text {in }}=10^{-3}\right.$, $r=0.75 \mathrm{~mm}$, and $K=10^{-3} \mathrm{~m}^{2} \mathrm{~s}^{-1}$ ) of (a) $T$ (black) and $T_{F}$ (blue), (b) $S$, and (c) $C$.

anomaly density perturbation that is under investigation in this section. We do this by using a nonhydrostatic, finite-element ocean model with a flexible unstructured mesh (Fluidity; Piggott et al. 2008). Fluidity has previously been used to develop a full multiphase model of fluid particle mixtures to simulate volcanic ash settling into water (Jacobs et al. 2012). Kimura et al. (2013) originally adapted Fluidity to the study of the ocean beneath ice shelves, and frazil ice was introduced into Fluidity by Jordan et al. (2014) in order to study freezing inside an ice shelf basal crevasse, using a modified version of the sediment model of Parkinson et al. (2014). In this study, velocity and pressure are discretized within first-order discontinuous and second-order continuous function spaces, respectively (a so-called $\mathrm{P}_{\mathrm{DG}}-\mathrm{P} 2$ finite-element pair), as described in Cotter et al. (2009). Scalar equations governing the conservation of heat, salt, and frazil ice concentration are discretized with a flux-limited control volume method (Piggott et al. 2009).

To investigate the full conditional instability of frazil ice growth, we first use a simple, two-dimensional box model $400 \mathrm{~m}$ deep by $200 \mathrm{~m}$ wide, with a 5 -m mesh resolution throughout. Unlike in the previous section, the water has a vertically uniform initial thermal driving $T^{*}=T_{\text {in }}^{*}$ except within the bottom $20 \mathrm{~m}$, which has $T^{*}=0$. A constant initial density gradient $\partial \rho / \partial z_{\text {in }}$ is imposed by salinity. The vertical uniform thermal driving and density gradient are a simplification for our idealized experiment; observations near ice shelves during frazil ice formation generally show depth varying thermal driving and density gradients (e.g., Mahoney et al. 2011). The bottom $20 \mathrm{~m}$ has an initial concentration of frazil ice $C_{\mathrm{in}}$, while the rest is ice free. Zero-flux Neumann boundary conditions for scalars and no-slip boundary conditions for velocity are applied in discretized space (weakly applied) at all boundaries except for frazil at the top boundary, which is allowed to deposit (Jordan et al. 2014).

Our baseline case has $C_{\text {in }}=10^{-3}, T_{\text {in }}^{*}=10^{-10} \mathrm{C}, \partial \rho / \partial z_{\text {in }}=$ $-10^{-5} \mathrm{~kg} \mathrm{~m}^{-4}$, frazil crystal radius $r=0.75 \mathrm{~mm}$, and $K=$ $10^{-3} \mathrm{~m}^{2} \mathrm{~s}^{-1}$ (Fig. 4). A sensitivity study around this baseline was carried out for a range of thermal drivings $\left(T_{\text {in }}^{*}=10^{-2}\right.$ to $\left.1^{\circ} \mathrm{C}\right)$, density gradients $\left(\partial \rho / \partial z_{\text {in }}=-10^{-3}\right.$ to $\left.-10^{-6} \mathrm{~kg} \mathrm{~m}^{-4}\right)$, frazil crystal radii $(r=0.25$ and $1.25 \mathrm{~mm})$, diffusivities/viscosities $\left(K=10^{-1}\right.$ and $\left.10^{-5} \mathrm{~m}^{2} \mathrm{~s}^{-1}\right)$ and initial frazil ice concentrations $\left(C_{\mathrm{in}}=2 \times 10^{-3}\right.$ and $5 \times$ $\left.10^{-4}\right)$. For the sensitivity study, all parameters except the one under investigation are held at their baseline value. The model is run for $12 \mathrm{~h}$ of simulation time, and at the end the total amount of frazil ice suspended in the water column and deposited on the top boundary is recorded. A stable case is deemed to be one where we have less frazil ice at the end of the run than the beginning, while an unstable case is one in which we have more. 


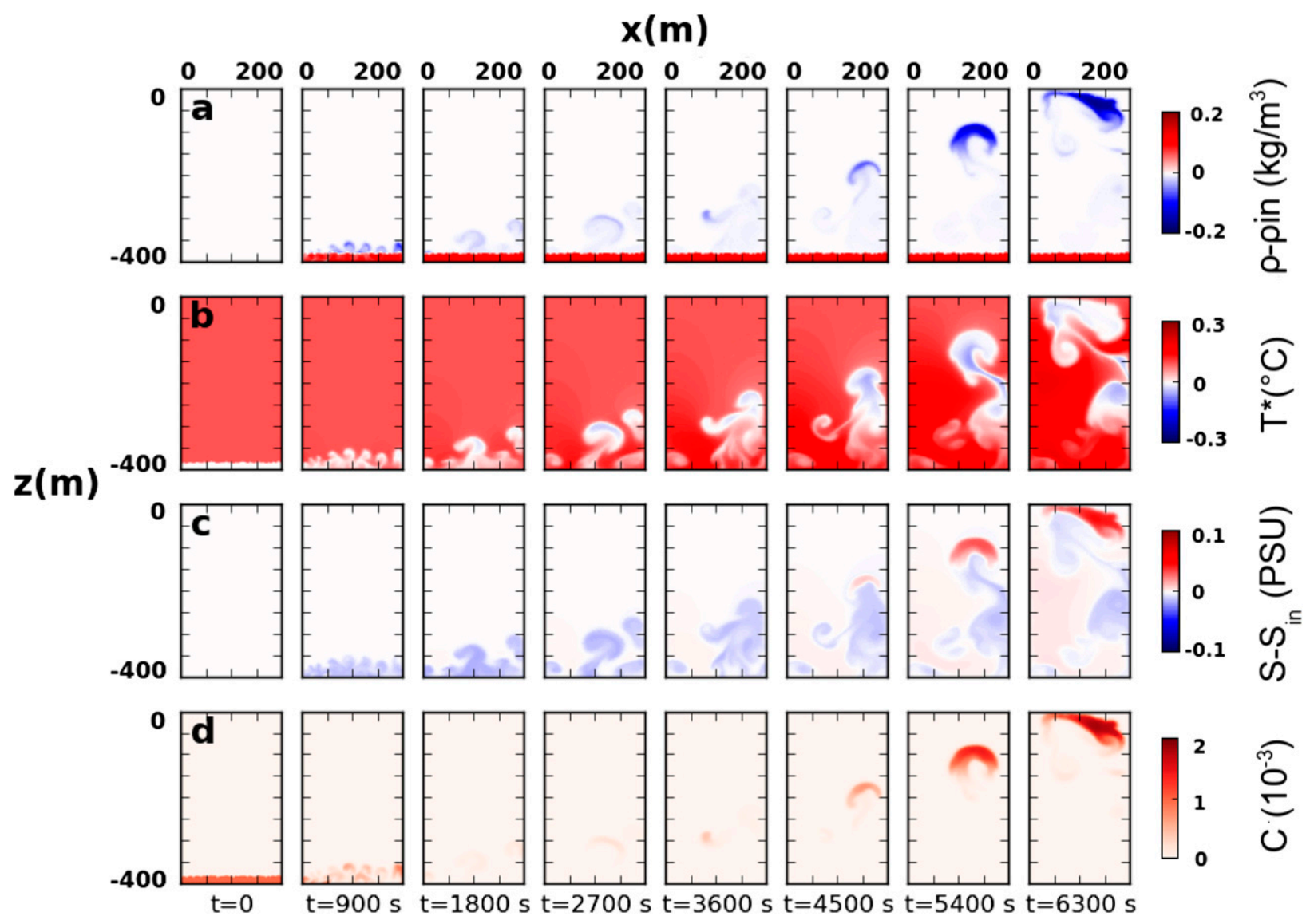

FIG. 5. Results of the idealized, nonhydrostatic ocean model setup. The time evolution of the instability for the unstable baseline case (all parameters as described for Fig. 4) in terms of (a) density relative to initial density, (b) thermal driving, (c) salinity relative to initial salinity, and (d) frazil ice concentration.

ISW plumes in nature are a mixture of a fresh anomaly and frazil ice. For simplicity, we do not provide the fresh anomaly perturbation explicitly in our simulations, but this perturbation is implicitly present in our choice of frazil perturbation $C_{\mathrm{in}}$. In our setup, if the frazil melts then the meltwater drives a conventional gravitational instability, which may or may not then be assisted by frazil regrowth. Because of the role of the fresh anomaly, this is a mixed instability. We consider the effect of this choice by also manufacturing a pure frazil instability by salt compensating the initial frazil concentration such that if all the frazil were to melt, there would be no initial density perturbation.

\section{b. Results}

The evolution of the instability in the base case is shown in Fig. 5. The initial density perturbation (defined as $\rho_{\text {in }}$, the initial density, minus $\rho$, the density of the iceseawater mixture) coalesces into separate "blooms" that merge as they rise. The maximum local density perturbation decreases in strength from around $t=900 \mathrm{~s}$ until it recovers at around $t=4500 \mathrm{~s}$, which is associated with a decline and reestablishment of the frazil. The density perturbation is largely manifested as a fresh anomaly perturbation during $t=1800-3600 \mathrm{~s}$. The interplay between density, thermal driving, and frazil ice concentration allows the growth of the instability, even if it is only manifested in frazil after $t=4500 \mathrm{~s}$. The largest density perturbations are caused by frazil ice, as illustrated by the density perturbation being present even when there is a positive salinity anomaly (e.g., $t=$ $5400 \mathrm{~s}$ ).

The instability can be suppressed in a number of ways (Fig. 6). These stable cases initially progress similarly to the unstable case (Fig. 6a), but following the initial melting of the frazil ice, the density perturbation never reestablishes itself. In the stratification-limited case, the perturbation does not rise quickly enough to overcome the frazil melting given by the thermal driving (Fig. 6b). In the thermally limited case, the thermal driving is too strong to be overcome by freezing temperature change even if the parcel is rising relatively quickly (Fig. 6c). 


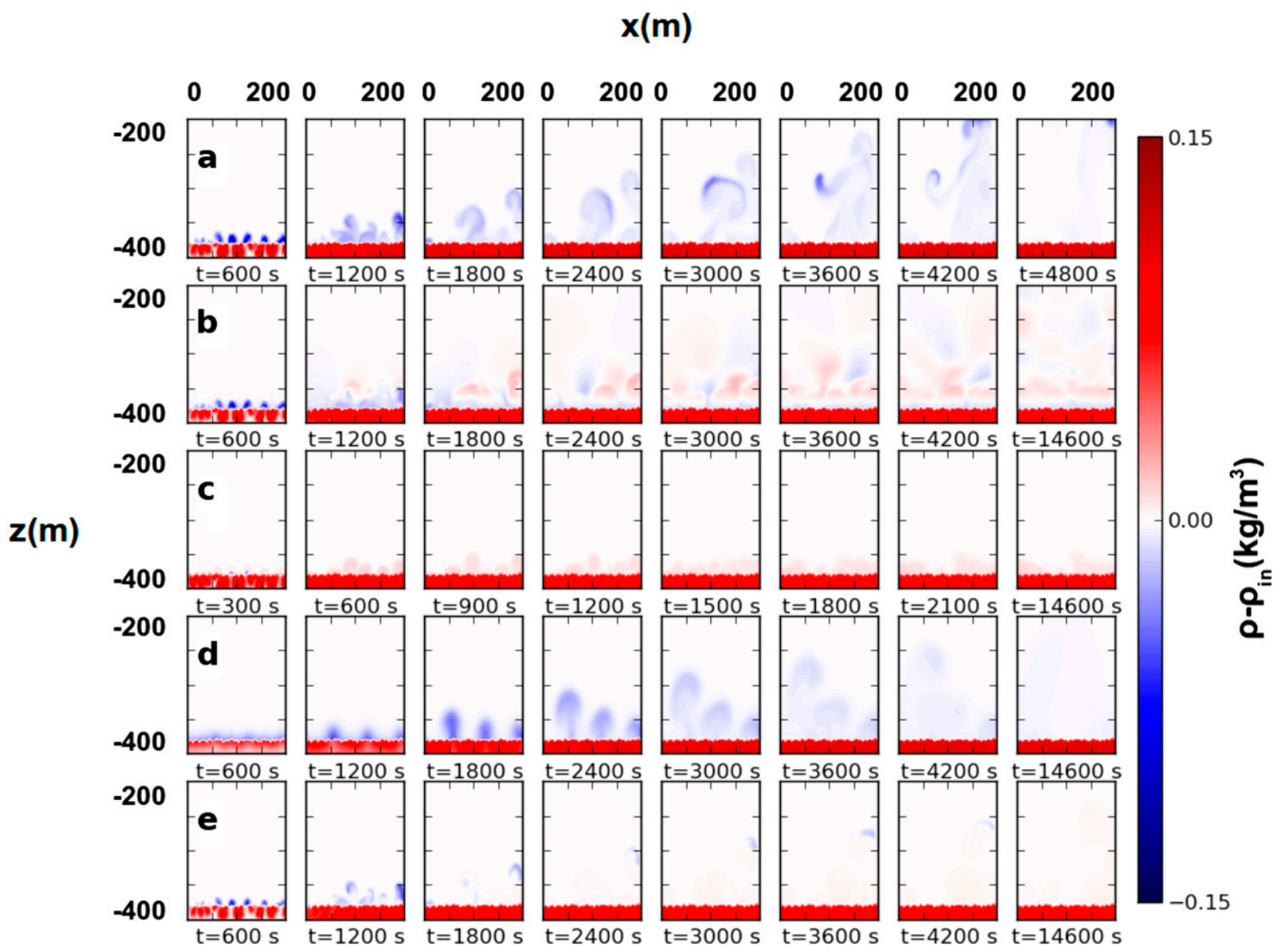

FIG. 6. Results of the idealized nonhydrostatic ocean model setup. Panels show the density of the combined frazil-seawater mixture relative to the initial density of (a) the baseline case (all parameters as described for Fig. 4) and also cases for which the instability is limited by (b) stratification $\left(\partial \rho / \partial z_{\text {in }}=-10^{-3} \mathrm{~kg} \mathrm{~m}^{-4}\right)$, (c) thermal driving $\left(T_{\mathrm{in}}^{*}=1^{\circ} \mathrm{C}\right)$, (d) background mixing $\left(K=10^{-1} \mathrm{~m}^{2} \mathrm{~s}^{-1}\right)$, and $(\mathrm{e})$ the salinity-compensated case where the salinity in the bottom $20 \mathrm{~m}$ has been increased by an amount equal to melting the initial frazil ice concentration. Note the different time axes.

The increased temperature outside the initial perturbation also reduces the magnitude of the density perturbation. In this particular case, the frazil-seawater mixture is lighter than the warmer water, but the equivalent fresh anomaly is not, so once the ice melts the instability is suppressed (see below). In the mixinglimited case, the perturbation follows the evolution of the stable case initially, but the density anomaly decreases because the background mixing erodes the negative density anomaly faster than it can rise (Fig. 6d).

This section considers a combined fresh anomaly/ frazil ice instability. To illustrate the role of frazil, a pure frazil instability can be simulated by setting an initial salt perturbation in the bottom $20 \mathrm{~m}$ of the model domain that precisely offsets the fresh anomaly input that would arise from the melting of the initial frazil ice. In this case, the density anomaly driving the instability is purely from frazil ice, and the instability does not cause increased frazil ice growth (Fig. 6e). Therefore, we conclude that in the baseline case the frazil is merely assisting an underlying gravitational instability.

The thermal stabilization of the baseline case (Fig. 6c) is a result of the combination of warming prohibiting frazil ice formation and also reducing the initial density perturbation. If the density difference caused by the warming is compensated by a freshening in the bottom $20 \mathrm{~m}$, pure thermal suppression of the frazil instability can be shown (Fig. 7). In contrast to the baseline of the Fig. 5 case, the density perturbation does not grow in size but reduces in magnitude as the water rises (Fig. 7a). The density perturbation does not rise quickly enough to overcome the warming and never freezes (Fig. 7b). The density perturbation in this particular case is driven solely by a fresh anomaly, as can be seen in the negative salinity anomaly (Fig.7c) and lack of frazil ice (Fig. 7d). 


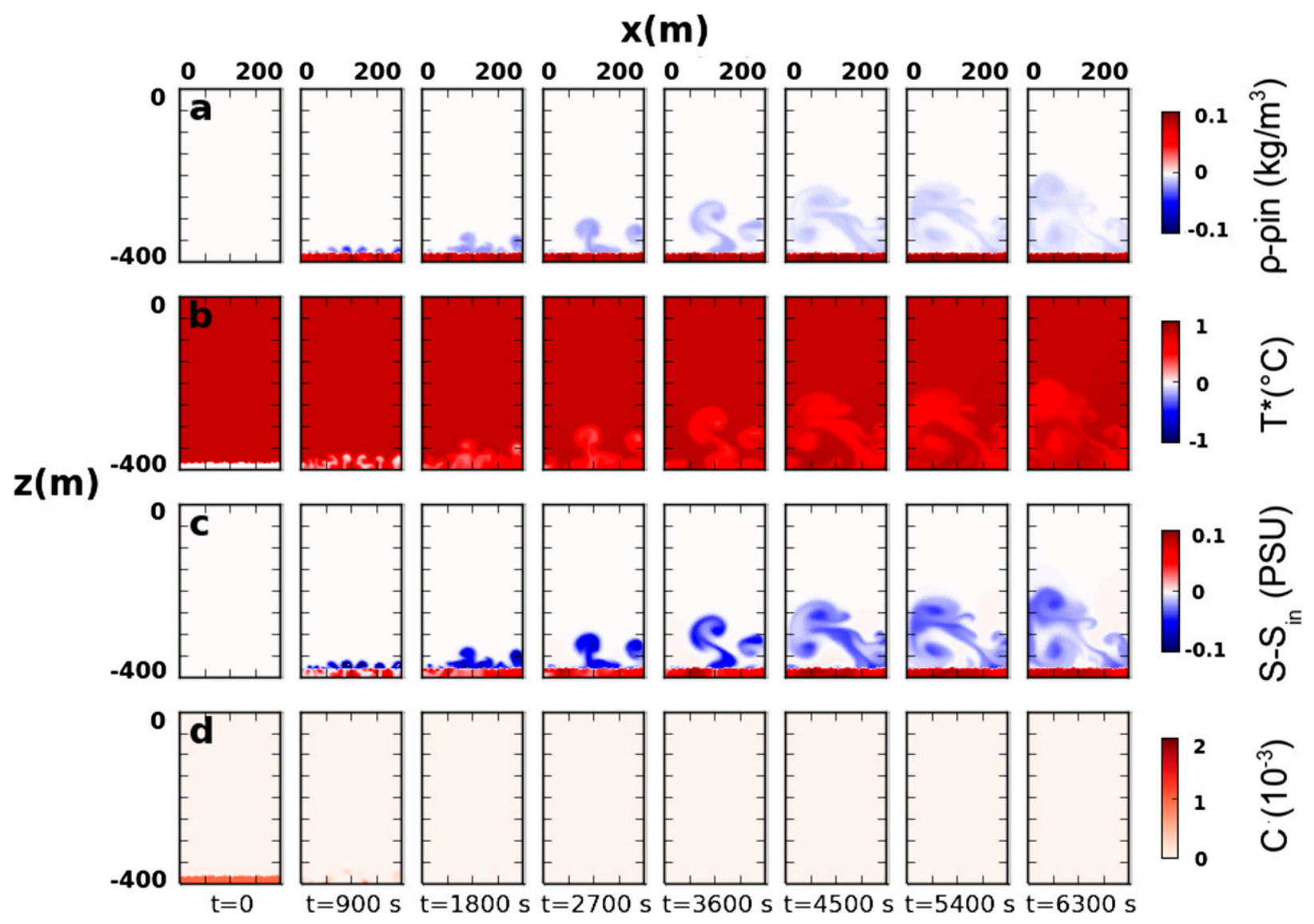

FIG. 7. Results of the idealized, nonhydrostatic ocean model setup. The instability for the purely thermally stable case $\left(T_{\text {in }}^{*}=1^{\circ} \mathrm{C}\right.$, $\partial \rho / \partial z_{\text {in }}=-10^{-5} \mathrm{~kg} \mathrm{~m}^{-4}, C_{\text {in }}=10^{-3}, r=0.75 \mathrm{~mm}$, and $K=10^{-3} \mathrm{~m}^{2} \mathrm{~s}^{-1}$ with salinity in the bottom $20 \mathrm{~m}$ reduced to compensate the $1^{\circ} \mathrm{C}$ warming of the rest of the domain) in terms of (a) density of the combined frazil-seawater mixture relative to the initial density, (b) thermal driving, (c) salinity relative to initial salinity, and (d) frazil ice concentration.

The effect of the varying thermal driving and density gradient upon overall frazil ice growth, while initial frazil ice concentration, background mixing, and frazil crystal radius are held constant, is shown in Fig. 8. The results are linearly interpolated between the set of discrete runs marked in white, with the white contour showing where the initial amount of frazil ice is the same as that at the end of the model run. We find significant instabilities forming in water that is initially above freezing. Decreasing the density gradient much beyond $\partial \rho / \partial z_{\text {in }}=-10^{-3} \mathrm{~kg} \mathrm{~m}^{-4}$ or increasing thermal driving beyond $T_{\text {in }}^{*}=10^{-1{ }^{\circ}} \mathrm{C}$ suppresses the instability, either by preventing the parcel from rising or by preventing it from supercooling as it rises. The zone of instability resembles the behavior found in the linear stability analysis (Fig. 2a), though the results are not directly comparable because of the difference in the background conditions. The exact area of the zone of instability for thermal driving and density gradient will depend upon the values of initial frazil ice concentration, background mixing, and frazil crystal radius used. A greater initial frazil ice concentration, for example, would promote the formation of the instability by lowering the necessary values of thermal driving and background mixing for the instability to be present. The general shape of the zone of instability, however, would remain the same.

The sensitivity of our results to higher and lower temperatures $\left(T_{\text {in }}^{*}=1{ }^{\circ} \mathrm{C}, T_{\text {in }}^{*}=10^{-2 \circ} \mathrm{C}\right)$, stratification $\left(\partial \rho / \partial z_{\text {in }}=-10^{-3} \mathrm{~kg} \mathrm{~m}^{-4}, \partial \rho / \partial z_{\text {in }}=-10^{-6} \mathrm{~kg} \mathrm{~m}^{-4}\right)$, frazil crystal radius $(r=0.125 \mathrm{~mm}, r=0.25 \mathrm{~mm})$, background mixing $\left(K=10^{-1} \mathrm{~m}^{2} \mathrm{~s}^{-1}, K=10^{-5} \mathrm{~m}^{2} \mathrm{~s}^{-1}\right)$, initial frazil concentration $\left(C_{\mathrm{in}}=2 \times 10^{-3}, C_{\mathrm{in}}=5 \times 10^{-2}\right)$, frazil rise velocity $\left(w_{i}=0 \mathrm{~m} \mathrm{~s}^{-1}\right)$, and the previously discussed pure (salinity compensated) case is shown in Fig. 9. Our baseline case can be separated into two phases: the first being an initial period of melting while the frazil ice is coalescing into a bloom (Fig 9a) and the second being a period of freezing as the bloom rises (Fig. 9b). 


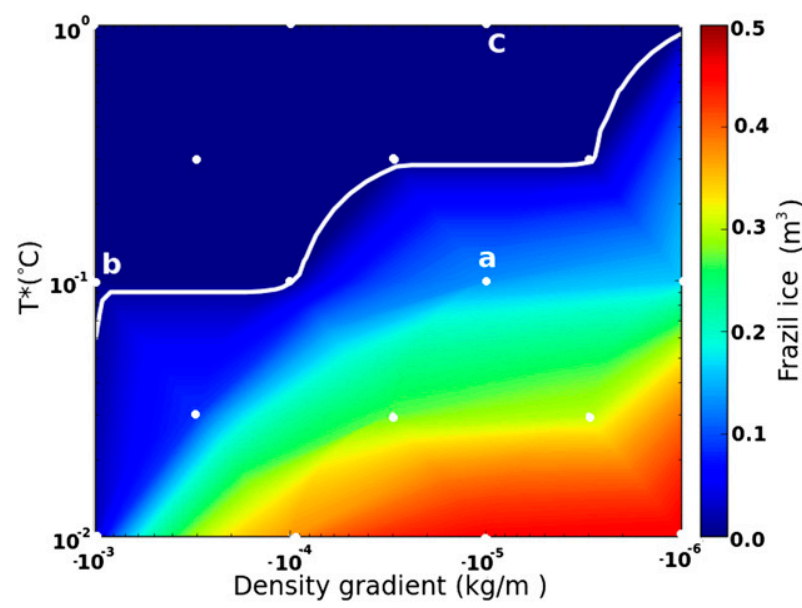

FIG. 8. Total frazil ice at the end of the idealized, nonhydrostatic ocean model simulation as a function of thermal driving and density gradient for $C_{\mathrm{in}}=10^{-3}, r=0.75 \mathrm{~mm}$, and $K=10^{-3} \mathrm{~m}^{2} \mathrm{~s}^{-1}$. Model runs were carried out for combinations of $T_{\text {in }}^{*}$ and $\partial \rho / \partial z_{\text {in }}$ marked in white, with results linearly interpolated between. The white contour shows where the initial frazil ice concentration is the same as the final frazil ice concentration. The final locations of the (a) baseline, (b) the stratification-limited case, and (c) the thermal driving-limited case shown in Fig. 6 are marked.

Our results are highly sensitive to temperature, with lower values of $T_{\text {in }}^{*}$ showing a rapid increase of frazil ice with only a small fraction of the initial melting seen in the baseline case. High $T_{\text {in }}^{*}$ cases rapidly melt the frazil ice, both in the baseline thermally stabilized case and the solely thermally stabilized case. Varying the density stratification has little impact on the initial melting period, but it does affect how quickly the frazil ice can rise and so impacts the freeze period. The low-stratification case shows an increased rate of freezing during this period, while the high-stratification case shows no freezing because the frazil-seawater mixture is unable to rise. The frazil crystal radius affects the rate at which the individual crystals freeze or melt, with larger crystals both melting and freezing slower than our baseline case because of the decreased ratio of surface area to volume. This can be seen in the delay of the onset of the freezing period, with the inverse true for the smaller frazil crystal radii. Increasing the diffusivity makes it harder for the frazil concentration to reach the critical volume needed for a buoyant bloom. Reducing the diffusivity has little impact on our results. By reducing the initial frazil concentration, and thus reducing the perturbation, we are able to shut down the instability as there is less initial buoyancy forcing driving the frazil rising. Similarly, increasing the initial concentration results in an increase in the final amount of frazil ice due to the increase of the initial buoyancy forcing. In the salinity-compensated case, the size of the initial density perturbation and buoyancy forcing has been reduced, shutting down the instability in a similar way to the smaller initial concentration case. Finally, by disabling the frazil rise velocity we see only a very slight increase in final frazil ice.

\section{Numerical modelling of an Ice Shelf Water outflow}

\section{a. Model setup}

Having investigated the combined frazil-fresh anomaly instability in a simple box model, we now use Fluidity to consider the suspended frazil ice observed in front of ice shelves in Antarctica. We model the area in front of an ice shelf by means of a two-dimensional domain $400 \mathrm{~m}$ deep by $2500 \mathrm{~m}$ wide, with a $20-\mathrm{m}$ mesh resolution used throughout (Fig. 10). The water has a constant initial thermal driving and a density gradient imposed by salinity. Diffusivities/viscosity of $K=$ $10^{-3} \mathrm{~m}^{2} \mathrm{~s}^{-1}$ are used. The top $300 \mathrm{~m}$ of the left boundary represents the front of an ice shelf with the bottom $100 \mathrm{~m}$ of the cavity underneath. The right boundary represents the ocean, the top boundary is the sea surface, and the bottom boundary is the sea bed. An inflow $U_{\text {in }}$ enters the domain at the bottom of the left side $(x=0)$ under steady Dirichlet boundary conditions $\left(u=U_{\text {in }}, w=0\right.$, $T^{*}=0, S=S_{\text {in }}$, and $C=0$ ) and leaves via the bottom $100 \mathrm{~m}$ of the right side $(x=2.5 \mathrm{~km})$ with zero-flux Neumann boundary conditions and $C=0$. By limiting the outflow to the bottom $100 \mathrm{~m}$ of the water column we aim to ensure that rising water is caused solely by the frazil instability, and the instability is pure in the sense that there is no density anomaly unless some frazil growth occurs. All frazil ice within the model is generated by the instability. No-slip boundary conditions are applied in discretized space (weakly applied) at all other boundaries. Zero-flux conditions for heat, salt, and frazil are applied at the seabed, top, and sides. The one exception to this is that frazil is allowed to deposit at the top and leave via the right-hand boundary. The total amount of frazil ice depositing on the top of the model domain is recorded after $24 \mathrm{~h}$ of simulation time.

\section{b. Results}

The evolution of a frazil ice bloom within the domain for the unstable baseline case $\left(T_{\text {in }}^{*}=10^{-2 \circ} \mathrm{C}, \partial \rho / \partial z_{\text {in }}=\right.$ $-10^{-6} \mathrm{~kg} \mathrm{~m}^{-4}, r=0.75 \mathrm{~mm}, K=10^{-3} \mathrm{~m}^{2} \mathrm{~s}^{-1}$, and $U_{\text {in }}=$ $0.05 \mathrm{~m} \mathrm{~s}^{-1}$ ) is shown in Fig. 11. As the inflow water is at the local freezing temperature, any upwards motion will cause frazil ice to form, though whether this is sufficient to create an instability depends on the factors previously discussed. Unlike in the previous section, the density perturbation is always dominated by frazil ice because of 

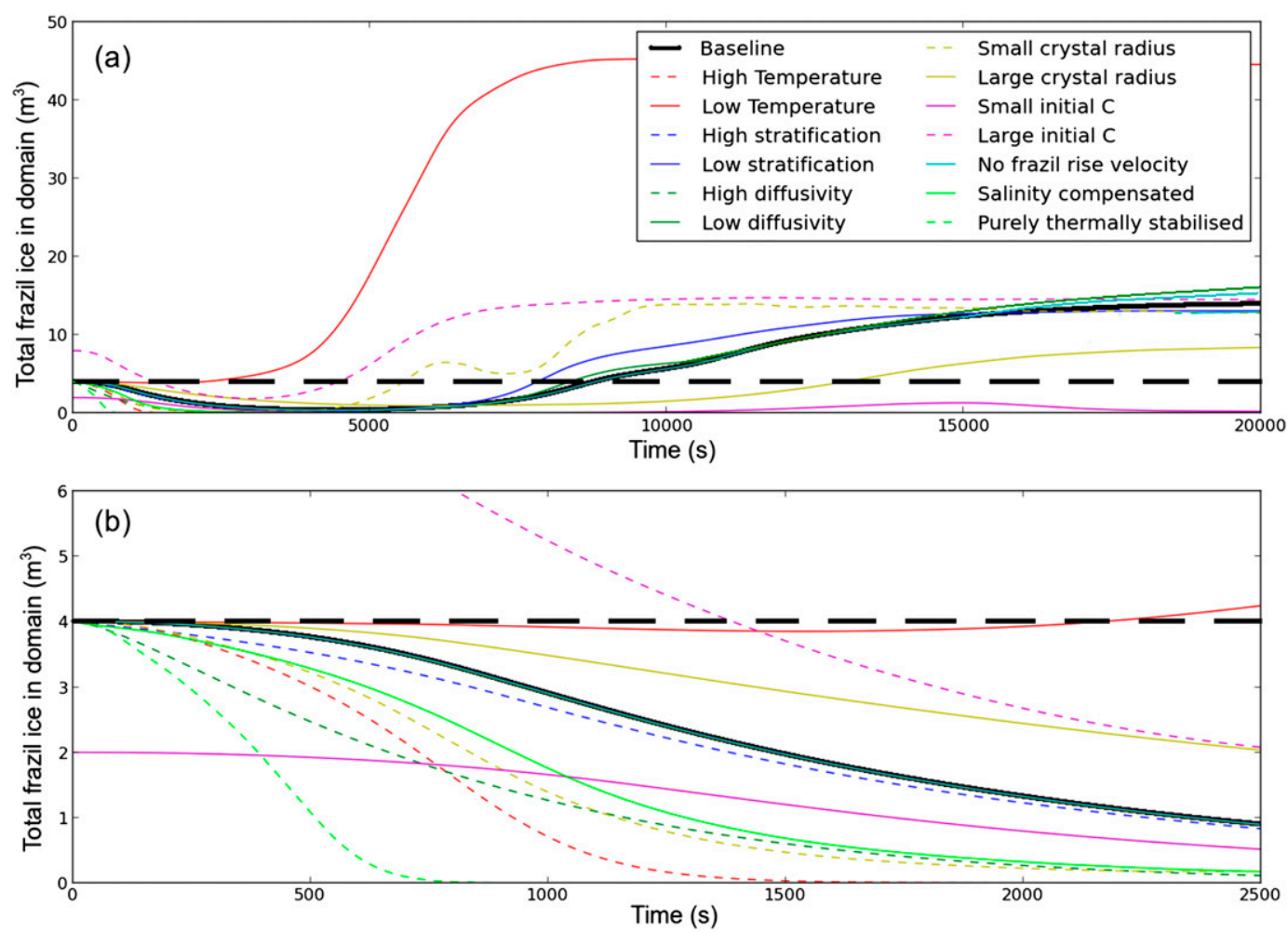

FIG. 9. Evolution of total frazil ice in the idealized nonhydrostatic ocean model for (a) the full $20000 \mathrm{~s}$ of the model run and (b) the first $2500 \mathrm{~s}$. The baseline case (all parameters as described for Fig. 4) is shown, and the black dashed line shows the amount of frazil ice at the start of the simulation. Also shown are the results of varying higher and lower temperatures $\left(T_{\text {in }}^{*}=1{ }^{\circ} \mathrm{C}, T_{\text {in }}^{*}=10^{-2 \circ} \mathrm{C}\right)$, stratification $\left(\partial \rho / \partial z_{\text {in }}=-10^{-3} \mathrm{~kg} \mathrm{~m}^{-4}, \partial \rho / \partial z_{\text {in }}=-10^{-6} \mathrm{~kg} \mathrm{~m}^{-4}\right)$, frazil crystal radius $(r=0.125 \mathrm{~mm}, r=0.25 \mathrm{~mm}), K\left(10^{-1} \mathrm{~m}^{2} \mathrm{~s}^{-1}, 10^{-5} \mathrm{~m}^{2} \mathrm{~s}^{-1}\right)$, initial frazil concentration $\left(C_{\mathrm{in}}=2 \times\right.$ $10^{-3}$ and $C_{\text {in }}=5 \times 10^{-2}$ ), salinity-compensated case (where salinity in the bottom $20 \mathrm{~m}$ has been increased to offset the fresh anomaly gained from melting the initial frazil ice concentration), pure thermally stabilized case (where salinity in the bottom $20 \mathrm{~m}$ has been reduced to offset the density change arising from the increase in temperature of the rest of the domain), and frazil rise velocity $\left(w_{i}=0 \mathrm{~m} \mathrm{~s}^{-1}\right)$, while keeping all other parameters at their baseline values.

our initial conditions; there is no period during which it is expressed as a fresh anomaly. The inflow causes a large amount of supercooling as it rises. Once the bloom of frazil ice begins at $t=13800 \mathrm{~s}$, there are corresponding areas of descending, salty waters. As before, frazil concentration has a greater effect on density than the salinity anomaly caused by freezing.

The dependence of mean frazil deposition on the density gradient and thermal driving over the domain (while background mixing and frazil crystal radius are

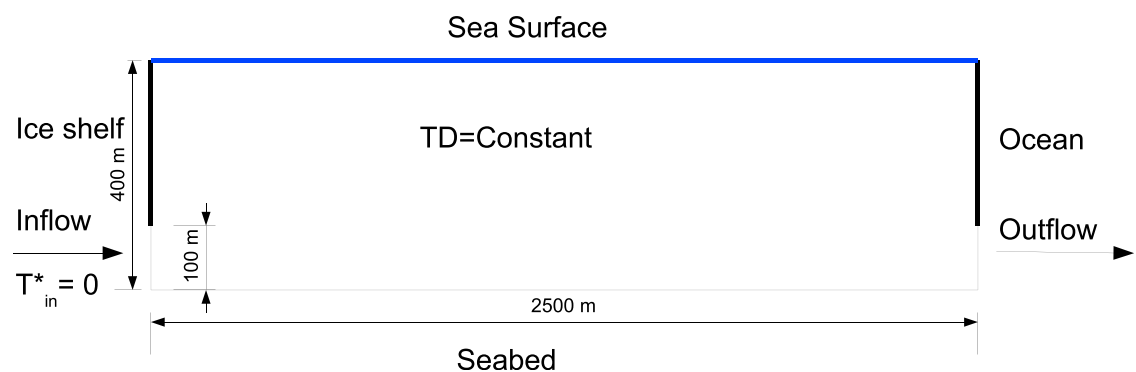

FIG. 10. Schematic of nonhydrostatic ice shelf model setup. An inflow enters the domain from the bottom $100 \mathrm{~m}$ on the right-hand side and leaves via the bottom $100 \mathrm{~m}$ on the right-hand side. The inflow water is at the freezing temperature, while the rest of the domain has a constant thermal driving. No frazil is present in the inflow or initial conditions. 

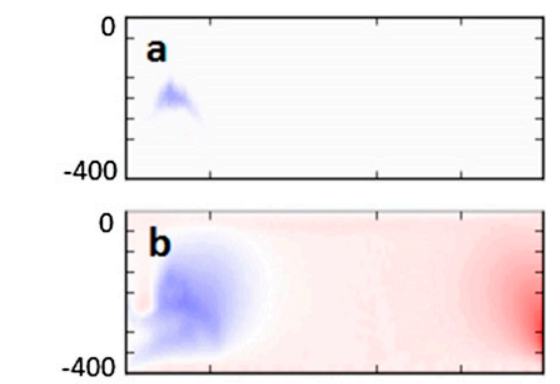

$\mathrm{z}(\mathrm{m})$
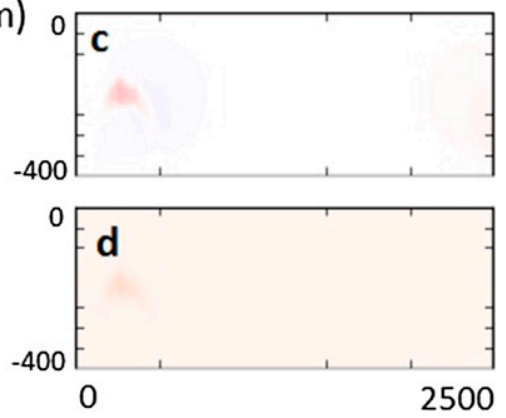

$\mathrm{t}=13200 \mathrm{~s}$
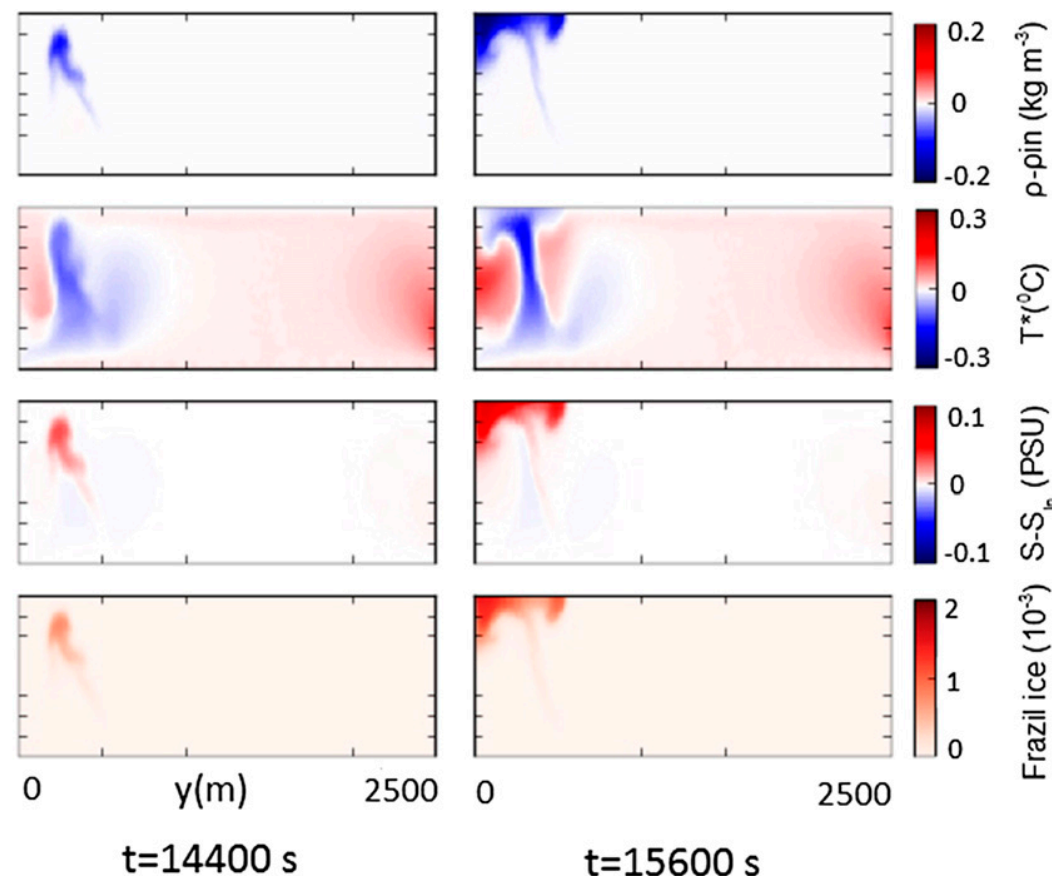

$t=15600 \mathrm{~s}$

\section{Time}

FIG. 11. Evolution of frazil ice growth in the nonhydrostatic ice shelf model for the baseline case all parameters as described for Fig. 4) in terms of (a) density relative to initial density, (b) thermal driving, (c) salinity relative to initial salinity, and (d) frazil ice concentration.

held constant) is shown in Fig 12. There is a strong agreement with our earlier results (Fig. 8), in that density gradients greater than $\partial \rho / \partial z_{\text {in }}=-10^{-3} \mathrm{~kg} \mathrm{~m}^{-4}$ and thermal driving greater than $T_{\text {in }}^{*}=10^{-1 \circ} \mathrm{C}$ will shut down the instability. The results are linearly interpolated between the set of discrete runs marked in white, with the white contour showing the line of zero frazil deposition. As before, the exact area of the "zone of instability" will vary with the frazil crystal radius and background mixing, but the general shape should remain the same. Mean frazil ice deposition at the sea surface is of the order of $0.1 \mathrm{mday}^{-1}$, a highly significant amount compared to typical growth rates of sea ice in winter.

We use the baseline case for a sensitivity study, with all parameters except the one under investigation held constant. Figure 13 shows the total amount of frazil ice deposited during $24 \mathrm{~h}$ as a function of distance from the ice front and the effects of varying thermal driving, diffusivities/viscosity, density gradient, crystal radius, inflow velocity, and simulation run time. Higher temperatures cause a decrease in the amounts of frazil deposited because of the increased frazil melt rate and, to a lesser extent, through density suppression of a frazilfresh anomaly. At $T_{\text {in }}^{*}=1^{\circ} \mathrm{C}$ there is no deposition of frazil ice (Fig. 13a). A higher value of $K$ has the effect of dispersing and smoothing the frazil deposition (Fig. 13b). Less frazil deposits with a stronger stratification, as the frazil-seawater mixture rises at a slower rate (Fig. 13c). A density gradient of $-10^{-3} \mathrm{~kg} \mathrm{~m}^{-4}$ is sufficient to stop the instability forming. By varying the crystal radius we can see that smaller radii form frazil at a much faster rate, and so the pattern of deposition is skewed towards the area

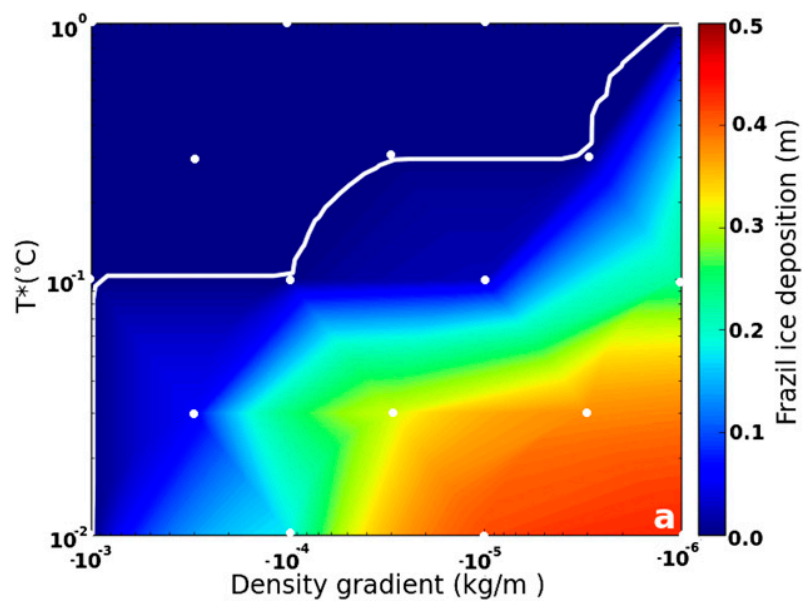

FIG. 12. Results of the nonhydrostatic Ice Shelf Water model setup. Spatial mean frazil ice deposition after $24 \mathrm{~h}$ as a function of thermal driving and density gradient for $r=0.75 \mathrm{~mm}$ and $K=$ $10^{-3} \mathrm{~m}^{2} \mathrm{~s}^{-1}$. Model runs were carried out for combinations of $T_{\text {in }}^{*}$ and $\partial \rho / \partial z_{\text {in }}$ marked in white, with results linearly interpolated between. The white contour shows the zero deposition contour. The location of (a) the baseline case is shown. 

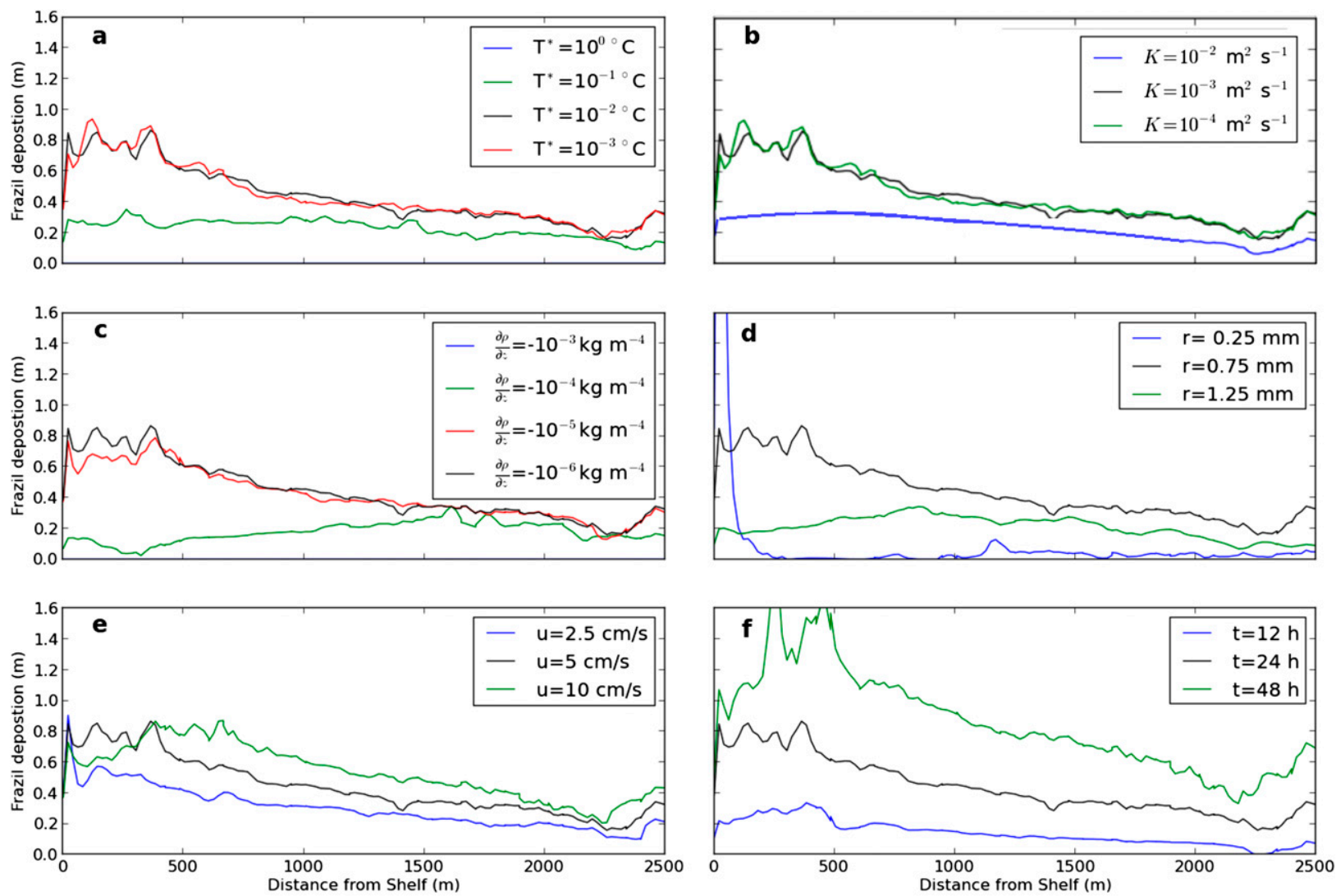

FIG. 13. Results of the nonhydrostatic Ice Shelf Water model setup. Sensitivity of frazil ice deposition after $24 \mathrm{~h}$ to (a) thermal driving, (b) background mixing, (c) stratification, (d) frazil crystal radius, (e) inflow velocity, and (f) time. In each case the baseline case is shown in black.

just in front of the ice front (Fig. 13d). A larger radius results in noticeably less deposition, at a greater distance, as the frazil crystals freeze at a slower rate because of the increased surface area to volume ratio. This is in agreement with the difference observed in Fig. 9. A greater inflow velocity (Fig. 13e) provides an increase in frazil deposition because of the larger volume flux of cold water into the model domain. Greater inflow velocities also move the peak of deposition away from the ice front. To put these "snapshot" results into context, we note that there is a relatively uniform increase in frazil deposition with time in the baseline case (Fig. 13f).

The model shows that frazil ice can deposit on the underside of sea ice a significant distance from the ice front of nearby ice shelves, a finding consistent with the model results of Hughes et al. (2014). The instability could be a process important in the known formation of frazil ice beneath sea ice in Antarctica (Leonard et al. 2006; Mahoney et al. 2011). The water conditions observed by Leonard et al. (2006) and Robinson et al. (2010) fall within the bounds that our results indicate for instabilities and frazil ice growth, given an initial perturbation from an ISW plume. Given the right conditions, the ice growth rates from frazil ice growth we find here are orders of magnitude greater than congelation sea ice growth.

\section{Conclusions}

We have investigated a conditional frazil ice-generated instability in seawater, first considering the response to an infinitesimal perturbation using a linear stability analysis and then the full conditional stability using a nonhydrostatic ocean model. We have also examined the effect of this instability upon ice growth in front of ice shelves. We draw the following conclusions:

1) Frazil ice growth caused by the rising of supercooled water is able to generate a buoyancy-driven instability even in a stably stratified fluid. The vertical distributions of temperature and salinity are therefore not the only source of overturning in the presence of near-freezing water. This buoyancydriven instability enhanced vertical mixing. 
2) In a marginally, gravitationally unstable water column, the frazil ice instability can coexist with the "background" convection. The convection becomes dominant as the background temperature and salinity are more unstable.

3) The instability does not operate in the presence of strong stratification, high thermal driving (warm water), a small initial perturbation, high background mixing, or the prevalence of large frazil ice crystals. It is largely unmodified by frazil crystals rising relative to their surrounding water.

4) ISW plumes in reality contain a mixture of frazil ice and a fresh anomaly, and as such the presence of a frazil ice instability can enhance an underlying fresh anomaly-driven density perturbation. The density perturbation driving the instability is not necessarily expressed in frazil ice at all times; an initial frazil perturbation may melt into a fresh anomaly perturbation that drives regrowth of ice.

5) Given a large enough initial perturbation this instability could allow significant rates of ice growth.

6) The model shows significant ice growth several kilometers from an ice shelf, under similar conditions to observations of frazil ice growth under sea ice. The presence of this instability could be a factor affecting the growth of sea ice near ice shelves, with implications for $\mathrm{AABW}$ formation.

\section{REFERENCES}

Clark, S., and J. Doering, 2006: Laboratory experiments on frazilsize characteristics in a counterrotating flume. J. Hydraul. Eng., 132, 94-101, doi:10.1061/(ASCE)0733-9429(2006)132:1(94).

Cotter, C. J., D. A. Ham, C. C. Pain, and S. Reich, 2009: LBB stability of a mixed Galerkin finite element pair for fluid flow simulations. J. Comput. Phys., 228, 336-348, doi:10.1016/ j.jcp.2008.09.014.

Daly, S. F., 1994: Evolution of frazil ice in natural water bodies. International Association for Hydraulic Research working group on thermal regimes: Report on frazil ice, U.S. Army Cold Regions Research and Engineering Laboratory Special Rep. 94-23, 19-24.

Dieckmann, G., G. Rohardt, H. Hellmer, and J. Kipfstuhl, 1986: The occurrence of ice platelets at $250 \mathrm{~m}$ depth near the Filchner Ice Shelf and its significance for sea ice biology. DeepSea Res., 33A, 141-148, doi:10.1016/0198-0149(86)90114-7.

Foldvik, A., and T. Kvinge, 1974: Conditional instability of sea water at the freezing point. Deep-Sea Res. Oceanogr. Abstr., 21, 169-174, doi:10.1016/0011-7471(74)90056-4.

_- and Coauthors, 2004: Ice Shelf Water overflow and bottom water formation in the southern Weddell Sea. J. Geophys. Res., 109, C02015, doi:10.1029/2003JC002008.

Gosink, J. P., and T. E. Osterkamp, 1983: Measurements and analyses of velocity profiles and frazil ice-crystal rise velocities during periods of frazil-ice formation in rivers. Ann. Glaciol., 4, 79-84.
Hellmer, H., and D. Olbers, 1989: A two-dimensional model for the thermohaline circulation under an ice shelf. Antarct. Sci., 1, 325-336, doi:10.1017/S0954102089000490.

Holland, P. R., and D. L. Feltham, 2005: Frazil dynamics and precipitation in a water column with depth-dependent supercooling. J. Fluid Mech., 530, 101-124, doi:10.1017/ S002211200400285X.

Hughes, K. G., P. J. Langhorne, G. H. Leonard, and C. L. Stevens, 2014: Extension of an Ice Shelf Water plume model beneath sea ice with application in McMurdo Sound, Antarctica. J. Geophys. Res. Oceans, 119, 8662-8687, doi:10.1002/ 2013JC009411.

Jacobs, C. T., G. S. Collins, M. D. Piggott, S. C. Kramer, and C. R. G. Wilson, 2012: Multiphase flow modelling of volcanic ash particle settling in water using adaptive unstructured meshes. Geophys. J. Int., 192, 647-665, doi:10.1093/gji/ggs059.

Jacobs, S. S., A. L. Gordon, and J. L. Ardai, 1979: Circulation and melting beneath the Ross Ice Shelf. Science, 203, 439-443, doi:10.1126/science.203.4379.439.

Jenkins, A., and A. Bombosch, 1995: Modeling the effects of frazil ice crystals on the dynamics of Ice Shelf Water plumes. J. Geophys. Res., 100, 6967-6981, doi:10.1029/94JC03227.

Jordan, J. R., P. R. Holland, A. Jenkins, M. D. Piggott, and S. Kimura, 2014: Modeling ice-ocean interaction in ice-shelf crevasses. J. Geophys. Res. Oceans, 119, 995-1008, doi:10.1002/ 2013JC009208.

Khazendar, A., and A. Jenkins, 2003: A model of marine ice formation within Antarctic ice shelf rifts. J. Geophys. Res., 108, 3235, doi:10.1029/2002JC001673.

Kimura, S., A. Candy, P. Holland, M. Piggott, and A. Jenkins, 2013: Adaptation of an unstructured-mesh, finite-element ocean model to the simulation of ocean circulation beneath ice shelves. Ocean Modell., 67, 39-51, doi:10.1016/ j.ocemod.2013.03.004.

Leonard, G. H., C. R. Purdie, P. J. Langhorne, T. G. Haskell, M. J. M. Williams, and R. D. Frew, 2006: Observations of platelet ice growth and oceanographic conditions during the winter of 2003 in McMurdo Sound, Antarctica. J. Geophys. Res., 111, C04012, doi:10.1029/2005JC002952.

Linden, P., 2000: Convection in the environment. Perspectives in Fluid Dynamics: A Collective Introduction to Current Research, G. K. Batchelor, H. K. Moffatt, M. G. Worster, Eds., Cambridge University Press, 289-345.

Mahoney, A. R., A. J. Gough, P. J. Langhorne, N. J. Robinson, C. L. Stevens, M. M. J. Williams, and T. G. Haskell, 2011: The seasonal appearance of Ice Shelf Water in coastal Antarctica and its effect on sea ice growth. J. Geophys. Res., 116, C11032, doi:10.1029/2011JC007060.

Martin, S., 1981: Frazil ice in rivers and oceans. Annu. Rev. Fluid Mech., 13, 379-397, doi:10.1146/annurev.fl.13.010181.002115.

McFarlane, V., M. Loewen, and F. Hicks, 2014: Laboratory measurements of the rise velocity of frazil ice particles. Cold Reg. Sci. Technol., 106-107, 120-130, doi:10.1016/ j.coldregions.2014.06.009.

McGuinness, M. J., M. J. M. Williams, P. J. Langhorne, C. Purdie, and J. Crook, 2009: Frazil deposition under growing sea ice. J. Geophys. Res., 114, C07014, doi:10.1029/2007JC004414.

Nicholls, K. W., and S. Østerhus, 2004: Interannual variability and ventilation timescales in the ocean cavity beneath FilchnerRonne Ice Shelf, Antarctica. J. Geophys. Res., 109, C04014, doi:10.1029/2003JC002149.

, S. Osterhus, K. Makinson, T. Gammelsrd, and E. Fahrbach, 2009: Ice-ocean processes over the continental shelf of the 
southern Weddell Sea, Antarctica: A review. Rev. Geophys., 47, RG3003, doi:10.1029/2007RG000250.

Parkinson, S. D., J. Hill, M. D. Piggott, and P. A. Allison, 2014: Direct numerical simulations of particle-laden density currents with adaptive, discontinuous finite elements. Geosci. Model Dev. Discuss., 7, 3219-3264, doi:10.5194/ gmdd-7-3219-2014.

Penrose, J. D., M. Conde, and T. J. Pauly, 1994: Acoustic detection of ice crystals in Antarctic waters. J. Geophys. Res., 99, 12573 12 580, doi:10.1029/93JC03507.

Piggott, M. D., G. J. Gorman, C. C. Pain, P. A. Allison, A. S. Candy, B. T. Martin, and M. R. Wells, 2008: A new computational framework for multi-scale ocean modelling based on adapting unstructured meshes. Int. J. Numer. Methods Fluids, 56, 10031015, doi:10.1002/fld.1663.

, P. Farrell, C. Wilson, G. Gorman, and C. Pain, 2009: Anisotropic mesh adaptivity for multi-scale ocean modelling. Philos. Trans. Roy. Soc., A367, 4591-4611, doi:10.1098/ rsta.2009.0155.
Price, D., W. Rack, P. J. Langhorne, C. Haas, G. Leonard, and K. Barnsdale, 2014: The sub-ice platelet layer and its influence on freeboard to thickness conversion of Antarctic sea ice. Cryosphere, 8, 1031-1039, doi:10.5194/tc-8-1031-2014.

Robinson, N. J., M. J. M. Williams, P. J. Barrett, and A. R. Pyne, 2010: Observations of flow and ice-ocean interaction beneath the McMurdo Ice Shelf, Antarctica. J. Geophys. Res., 115, C03025, doi:10.1029/2008JC005255.

Schmitt, R. W., 1994: Triangular and asymmetric salt fingers. J. Phys. Oceanogr., 24, 855-860, doi:10.1175/1520-0485(1994)024<0855: TAASF $>2.0 . \mathrm{CO} ; 2$.

Smetacek, V., R. Scharek, L. I. Gordon, H. Eicken, E. Fahrbach, G. Rohardt, and S. Moore, 1992: Early spring phytoplankton blooms in ice platelet layers of the southern Weddell Sea, Antarctica. Deep-Sea Res., 39A, 153-168, doi:10.1016/ 0198-0149(92)90102-Y

Ye, S. Q., J. Doering, and H. T. Shen, 2004: A laboratory study of frazil evolution in a counter-rotating flume. Can. J. Civ. Eng., 31, 899-914, doi:10.1139/104-056. 